International Journal of Engineering, Science and Technology

Vol. 10, No. 1, 2018, pp. 50-75
INTERNATIONAL JOURNAL OF ENGINEERING, SCIENCE AND TECHNOLOGY

www.ijest-ng.com

www.ajol.info/index.php/ijest

(C)2018 MultiCraft Limited. All rights reserved

\title{
Heat transfer in a vertical rectangular duct filled with a porous matrix and saturated with a nanofluid for temperature dependent viscosity
}

\author{
J.C. Umavathi \\ Department of Mathematics, Gulbarga University, Kalaburgi-585 106, Karnataka, INDIA \\ "Corresponding Author: e-mail: drumavaathi@ rediffmail.com
}

\begin{abstract}
This paper presents the results of a comprehensive numerical study to analyze free convective heat transfer in a vertical rectangular duct filled with porous matrix and saturated with nanofluid for temperature dependent viscosity. Using the DarcyForchhiemer model, the momentum in the porous medium was simulated. While insulating two opposing wall ducts, the temperatures remained varied for the other two walls. Solutions to the transport equations for a Newtonian fluid were provided numerically through the finite difference approach to second order accuracy. The impact of the overriding parameters, for instance, the parameters of variable viscosity as well as inertial, the Grashof number, Darcy number, Brinkman number, solid volume index as well as the aspect ratio having a water-Copper nanofluid on the flow characteristics of natural convection is investigated. The flow nature using different nanoparticles is also studied. The values of volumetric flow rate, skin friction and Nusselt number are tabulated for pertinent parameters. It is found that for negative values of viscosity variation parameter the flow is enhanced in the lower part of the duct and positive values will enhance the flow in the upper part of the duct. Silver nanoparticle attains the maximum heat transfer rate when compared to other nanoparticles.
\end{abstract}

Keywords: Natural convection; Darcy-Forchhiemer model; Nanofluids; Variable viscosity; Viscous dissipation; Rectangular duct; Finite difference method.

DOI: http://dx.doi.org/10.4314/ijest.v10i1.5

\section{Introduction}

A broadly publicised research domain in the fluid mechanics literature, which concerns natural phenomena, is the phenomenon relating to convective motion, which is propelled through the buoyancy force. In this research interest area, the phenomenon of buoyancy for situations in porous media has been a major aspect of theoretical formulations and dimensions. Of particular interest, the influences of non-Dancy on natural convection in porous media became almost routine discussions among scholars. Of course, the motivation for these regular discussions is the usefulness of the techniques in a wide array of technical applications, including the flow of fluids in reservoirs (geothermal), in chemical manufacturing for separation processes, in soil water application where the dispersion o9f contaminants (chemical) by the way of water-saturated soil, in casting where solidification is required as well as in grain storage schemes where moisture immigrates, etc. A broad survey of literature relative to this discussion could be obtained in Kaviany (1995), Ipp and Ingham (2001) as well as Bejan et al. (2004).

The specific attention to the Brinkman-broadened Darcy representation was documented by Tony and Subramanian (1985) as well as Lauriat and Prasad (1987) to analyse the impacts of buoyancy on free convection for a vertical cavity. This representation was at just introduced in 1947 by Brinkman in an attempt to take care of the transaction of flow to highly 
viscous flow (devoid of porous matrix) arising from Darcy flow, within the restriction of outstandingly elevated permeability. Nevertheless, the contribution of Brinkman (i.e. Brinkman's model) fails to completely treat the idea of transition from porous-medium flow to pure fluid flow in situations of increases in the porous-medium's permeability. A representation that bridges the complete gap arising between the Darcy and Navier-Stokes equation is the model by Dancy-Forchheimer that was built up through Vafai as well as Tien (1981).

As the velocity of the fluid becomes elevated while the heat transfer is contemplated in the near-wall region, the observation is that the inertial and boundary impacts glow substantially (Chen and Lin, 1985). Furthermore, the DarcyForchheimer model showcases the impact of inertial and viscous forces in porous media, which was employed by Poulikakos (1985) as well as Lauriat and Prasad (1989) to analyse the natural convection occurring in a vertical enclosure that is filled with a porous medium. Umavathi et al. (2005, 2012a, 2012b, 2013a, 2013b, 2013c, 2013d) studied the heat transfer as well as flow in vertical channels and ducts, employing Darcy- Forchheimer model. At present, despite intensive scholarly activities aimed at improving outcomes of industrial heat transfer through fluid mechanics, the restricted capability associated with conventional fluids, for instance, oil, ethylene-glycol and water, to transfer heat has remained a strong confrontation in the science of heat transfer. Fortunately, the replacement of conventional fluids by superior fluids having elevated thermal conductivity has been an approach to getting rid of this challenge. These advanced fluids were meant to be just fluids in theory in a long period of time, pending the emergence of the quick build-up of the nanotechnology movement.

Surprisingly, nanotechnology restores the hope and confidence of building up competent heat exchangers through the emergence of a novel aspect of fluids, referred to as nanofluids. The creation of nanofluids is often achieved through the dispense of little amounts of metal or semi-metal particulates, having dimensions to the tune of $100 \mathrm{~mm}$ into a standard base fluid, for instance, oil or water. Over the past ten years, substantial improvements in thermal conductivity modeling and the use of convective heat transfer concerning nanofluids that are superior to predictions are at present available in microscopic models (Li and Xuan, 2002; Wang et al; 1999; He at al., 2007). In an instance, He et al. (2007) asserted the respective 6\% and $12 \%$ increase over water compared with the thermal; conductivity as well as the convective heat transfer coefficient of $1.2 \% \mathrm{~T}_{\mathrm{i}} \mathrm{O}_{2}$-water nanofluids. The nanoparticles in nanofluids are capable of flowing through media that are permeable while these flows could enhance the recovery of oil. The stability analysis using nanofluids was discussed by Umavathi and Monica (2014a, 2014b, 2016) and Umavathi (2015). The employment of nanoparticles is as well common to determine the changes in the saturation of fluids as well as the reservation properties in the course of production of oil and gas. In attempt to enhance viscous oil recovery, a fluid, for instance, water, is injected into the porous medium for a displacement of the oil since water has viscosity lower than that of oil. Nevertheless, a growth in the injected fluid's viscosity (e.g. through the employment of nanofluids) would substantially enhance the efficiency of recovery.

Hady et al. (2011a, 2011b, 2014) published series of papers using nanofluid to analyse the influence of yield stress past a vertical plane that is saturated through porous medium. A model based on non-homogeneous equilibrium, consisting of two components and four equations was credited to Buongiomo (2006) and the use was for mass, momentum as well as heat transfer in nanofluids. By employing Buongiomo's (2006) model, Kwang et. al. (2009), Nield and Kuznestsov (2009), Umavathi (2013a, b), Umavathi and Shekar (2015), Umavathi et al. (2015) analysed the effects of the presence of nanoparticles in nanofluids. Recently, Ed et al. (2015) discussed about the effectiveness of a chemical reaction on the viscous flow of a non-Darcy nanofluid over a non-nearly stretching sleet in a porous medium. Further, Ed (2016) extended his studies in Ed et al. (2015) including the impact of heat generation for an electrically conducting fluid.

A major part of currently available analytical investigations regarding this problem are rooted in uniform physical properties for the fluid (ambient). Nevertheless, it is clear (consider Herwing and Gresten 1986) that these physical properties are subjected to changes in temperature, particularly fluid viscosity. Thus, in order to predict the flow as well as the heat transfer rates from an accurate perspective, it becomes essential to account for this variation regarding viscosity in the analysis of the problem. Sedeek (2002) considered the impact of magnetic field as well as variable viscosity on the forced non-Darcy flow concerning a flat plate having variable wall temperature in porous media considering suction as well as blowing. Furthermore, Umavathi and her group (2015a, b, c, d, 2016a, b, c) analyzed the natural convection having temperature-dependent viscosity and thermal conductivity in a duct and square cavity.

The immense application of nanofluids in the field of technology and to understand the flow nature close to the more real prediction of the flow nature by considering the variable properties, motivated to take this problem under investigation. This problem is an extension of Umavathi and Odelu (2015d) replacing the clear fluid by a nanofluid saturated with the porous medium.

\section{Mathematical Formulation}

Consider a steady fully developed laminar flow of a nanofluid saturated with porous matrix in a long vertical rectangular duct. The geometry of the problem is shown in Fig. 1, where the cartesian co-ordinate system $(X, Y, Z)$ is located as shown in the physical configuration. $a$ and $b$ are length and breadth of the duct in $Z$ and $Y$ directions 
respectively. Since the flow is fully developed, the velocity components in the $X$ and $Y$ directions are zero, and consequently, the velocity vector of the fluid is given as $W=W(X, Y)$. The duct walls are assumed to be rigid and impermeable. The porous medium is homogeneous and isotropic. The non-Darcian model including the effect of inertial forces and taking into account the effect of viscous and Darcy dissipations is incorporated in defining the model. The fluid is assumed to be incompressible and the effective viscosity is equal to the viscosity of the fluid. The physical properties characterizing the fluid except density and viscosity are assumed to be constant. As customary, the Boussinesq approximation and the equation of state $\rho=\rho_{0}\left(1-\beta\left(T-T_{0}\right)\right)$ will be adopted. The two sides of the duct are maintained at constant different temperatures $T_{1}$ at $Y=0$ and $T_{2}$ at $Y=b$, where $T_{2}>T_{1}$ and $\partial T / \partial X=0$ at $X=0$ and at $X=a$.

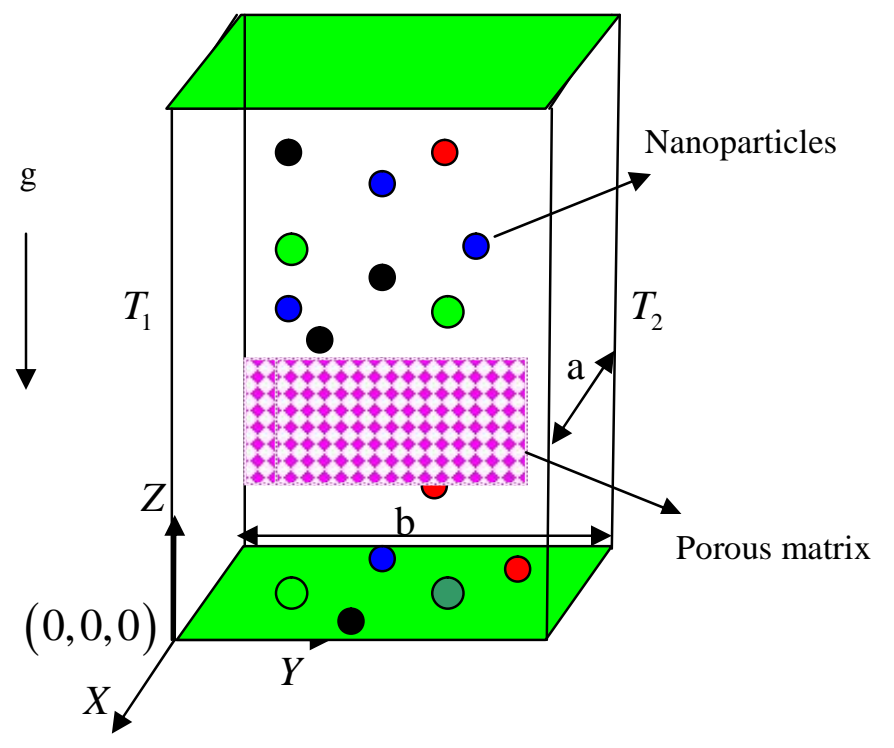

Figure 1: Physical configuration

Water is used as a base fluid and spherical nanoparticles such as Copper, Titanium Oxide Diamond, and Silicon Oxide are considered for the study. The base fluid and the nanoparticles are assumed to be in thermal equilibrium. Fluid rises in the duct driven by buoyancy forces. The flow is fully developed and the following relations apply here

$U=V=0, \quad \frac{\partial U}{\partial X}=\frac{\partial U}{\partial Y}=\frac{\partial V}{\partial X}=\frac{\partial V}{\partial Y}=0, \quad \frac{\partial P}{\partial X}=\frac{\partial P}{\partial Y}=\frac{\partial P}{\partial Z}=0$

The continuity equation gives $\partial W / \partial Z=0$ and therefore $W=W(X, Y)$. Under these assumptions, equations governing the fluid flow and heat transfer are as follows (Umavathi, 2015b)

$$
\begin{aligned}
& \frac{\partial}{\partial X}\left(\mu_{n f} \frac{\partial W}{\partial X}\right)+\frac{\partial}{\partial Y}\left(\mu_{n f} \frac{\partial W}{\partial Y}\right)+g(\rho \beta)_{n f}\left(T-T_{0}\right)-\frac{\mu_{n f}}{\kappa} W-\frac{\rho_{n f} C_{F}}{\sqrt{\kappa}} W^{2}=0 \\
& \frac{\partial^{2} T}{\partial X^{2}}+\frac{\partial^{2} T}{\partial Y^{2}}+\left(\frac{\mu}{K}\right)_{n f}\left[\left(\frac{\partial W}{\partial X}\right)^{2}+\left(\frac{\partial W}{\partial Y}\right)^{2}\right]+\frac{\mu_{n f}}{K_{n f} \kappa} W^{2}=0
\end{aligned}
$$

The relevant boundary conditions for the problem under study are as follows 


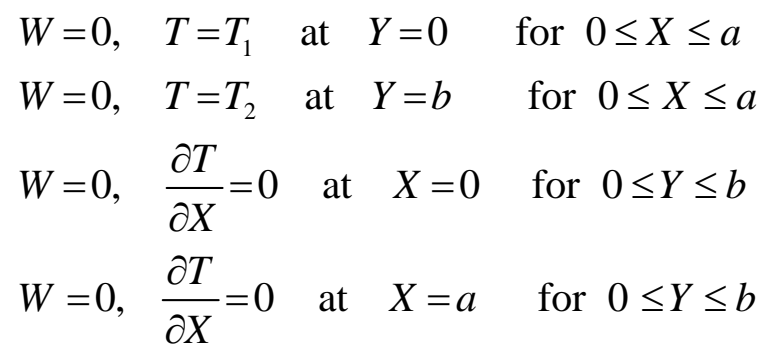

The effective density of the nanofluid is given as

$\rho_{n f}=(1-\phi) \rho_{f}+\phi \rho_{s}$

where $\phi$ is the solid volume fraction of the nanoparticles. The thermal diffusivity, heat capacitance and thermal expansion coefficients of the nanofluid respectively are given by

$\alpha_{n f}=\frac{K_{n f}}{\left(\rho C_{p}\right)_{n f}}$
$\left(\rho C_{p}\right)_{n f}=(1-\phi)\left(\rho C_{p}\right)_{f}+\phi\left(\rho C_{p}\right)_{s}$
$(\rho \beta)_{n f}=(1-\phi)(\rho \beta)_{f}+\phi(\rho \beta)_{s}$

The effective dynamic viscosity of the nanofluid given by Brinkman (1952) is

$\mu_{n f}=\frac{\mu_{f}}{(1-\phi)^{2.5}}$

In equation (6), $K_{n f}$ is the thermal conductivity of the nanofluid. For spherical nanoparticle, according to Maxwell (1904), this can be written as

$$
K_{n f}=K_{f} \frac{K_{s}+2 K_{f}-2 \phi\left(K_{f}-K_{s}\right)}{K_{s}+2 K_{f}+\phi\left(K_{f}-K_{s}\right)}
$$

Here the subscripts $n f, f$ and $s$ respectively are the thermo physical properties of the nanofluid, base fluid and the solid nanoparticles.

The fluid viscosity $\mu_{f}$ is assumed to vary with temperature as $\mu_{f}=\mu_{0} \exp \left\{-c\left(T-T_{0}\right)\right\}$ where the subscript 0 denotes the reference state and " $c$ " is an empirical constant. The parameter " $c$ " may take positive values for liquids such as water, benzene or crude oil. In some gases like air, helium or methane " $c$ " may be negative, i.e., the coefficient of viscosity increases with temperature. This type of model can find applications in many processes where preheating of the fuel is used as a means to enhance heat transfer effects. In addition, for many fluids such as lubricants, polymers, and coal slurries where viscous dissipation is substantial, an appropriate constitutive relation where viscosity is a function of temperature should be used.

Equations (1) to (4) are non-dimensionalised using the following dimensionless parameters

(Buongiorno, 2006)

$$
\begin{aligned}
& x=X / b, y=Y / b, w=\left(W \rho_{f} b\right) / \mu_{0}, \theta=\left(T-T_{0}\right) /\left(T_{2}-T_{1}\right), T_{0}=\left(T_{1}+T_{2}\right) / 2, \\
& G r=\left(g \beta_{f} \Delta T b^{3} \rho_{f}^{2}\right) / \mu_{0}^{2}, B r=\mu_{0}^{3} /\left(K_{f} \Delta T \rho_{f}^{2} b^{2}\right), \quad D a=\kappa / b^{2}, I=\left(C_{F} b\right) / \sqrt{\kappa}, B V=c \Delta T,
\end{aligned}
$$

The dimensionless momentum and energy equations become

$$
\begin{aligned}
& \frac{\partial w}{\partial x} \frac{\partial \exp (-B V \theta)}{\partial x}+\frac{\partial^{2} w}{\partial x^{2}} \exp (-B V \theta)+\frac{\partial w}{\partial y} \frac{\partial \exp (-B V \theta)}{\partial y}+\frac{\partial^{2} w}{\partial y^{2}} \exp (-B V \theta)+ \\
& +G r(1-\phi)^{2.5}\left\{(1-\phi)+\phi \frac{(\rho \beta)_{s}}{(\rho \beta)_{f}}\right\} \theta-\exp (-B V \theta) \frac{w}{D a}-I(1-\phi)^{2.5}\left[(1-\phi)+\phi \frac{\rho_{s}}{\rho_{f}}\right] w^{2}=0
\end{aligned}
$$




$$
\begin{aligned}
& \frac{\partial^{2} \theta}{\partial x^{2}}+\frac{\partial^{2} \theta}{\partial y^{2}}+\frac{B r \exp (-B V \theta)}{(1-\phi)^{2.5}}\left(\frac{K_{s}+2 K_{f}+\phi\left(K_{f}-K_{s}\right)}{K_{s}+2 K_{f}-2 \phi\left(K_{f}-K_{s}\right)}\right)\left[\left(\frac{\partial w}{\partial x}\right)^{2}+\left(\frac{\partial w}{\partial y}\right)^{2}\right] \\
& +\frac{B r \exp (-B V \theta)}{D a(1-\phi)^{2.5}}\left(\frac{K_{s}+2 K_{f}+\phi\left(K_{f}-K_{s}\right)}{K_{s}+2 K_{f}-2 \phi\left(K_{f}-K_{s}\right)}\right) w^{2}=0
\end{aligned}
$$

The non-dimensional boundary conditions used to solve the Eqs. (12) and (13) are $w=0, \theta=-0.5$ at $y=0$ for $0 \leq x \leq A$

$w=0, \theta=0.5$ at $y=1$ for $0 \leq x \leq A$

$w=0, \frac{\partial \theta}{\partial x}=0$ at $x=0$ and $x=A$ for $0 \leq y \leq 1$

\section{Solution Method}

The governing equations (12) and (13) defining the model along with boundary conditions (14) are coupled and nonlinear and hence closed form solutions are out of reach. Therefore we find the approximate solutions using the numerical methods. The finite difference technique is opted for the numerical method. In this method the computational domain is divided into a uniform grid system. The second-derivative and the squared first-derivative terms are discretized using the central difference of second-order accuracy. The finite difference form of $\partial^{2} w / \partial x^{2}$ and $\partial w / \partial x$, for example, were discretized as $\frac{\partial^{2} w}{\partial x^{2}}=\frac{w_{i+1, j}-2 w_{i, j}+w_{i-1, j}}{\Delta x^{2}}+O\left(\Delta x^{2}\right)$ and $\frac{\partial w}{\partial x}=\frac{w_{i+1, j}-w_{i-1, j}}{2 \Delta x}+O\left(\Delta x^{2}\right)$, respectively. Substituting the above differences in Eqs. (12) and (13) reduces to the following difference equations.

$$
\begin{aligned}
& \left(\frac{w_{i+1, j}-w_{i-1, j}}{2 \Delta x}\right)\left(-B V \exp \left(-B V \theta_{i, j}\right)\right)\left[\frac{\theta_{i+1, j}-\theta_{i-1, j}}{2 \Delta x}\right]+\exp \left(-B V \theta_{i, j}\right)\left(\frac{w_{i+1, j}-2 w_{i, j}+w_{i-1, j}}{\Delta x^{2}}\right) \\
& +\left(\frac{w_{i, j+1}-w_{i, j-1}}{2 \Delta y}\right)\left(-B V \exp \left(-B V \theta_{i, j}\right)\right)\left[\frac{\theta_{i, j+1}-\theta_{i, j-1}}{2 \Delta y}\right]+\exp \left(-B V \theta_{i, j}\right)\left(\frac{w_{i, j+1}-2 w_{i, j}+w_{i, j-1}}{\Delta y^{2}}\right) \\
& +G r(1-\phi)^{2.5}\left\{(1-\phi)+\phi \frac{(\rho \beta)_{s}}{(\rho \beta)_{f}}\right\} \theta_{i, j}-\exp (-B V \theta) \frac{w_{i, j}}{D a}-I(1-\phi)^{2.5}\left[(1-\phi)+\phi \frac{\rho_{s}}{\rho_{f}}\right] w_{i, j}{ }^{2}-=0 \\
& \frac{\theta_{i+1, j}-2 \theta_{i, j}+\theta_{i-1, j}}{\Delta x^{2}}+\frac{\theta_{i, j+1}-2 \theta_{i, j}+\theta_{i, j-1}}{\Delta y^{2}}+\left(\frac{K_{s}+2 K_{f}+\phi\left(K_{f}-K_{s}\right)}{K_{s}+2 K_{f}-2 \phi\left(K_{f}-K_{s}\right)}\right\}\left[\left(\frac{w_{i+1, j}-w_{i-1, j}}{2 \Delta x}\right)^{2}+\left(\frac{w_{i, j+1}-w_{i, j-1}}{2 \Delta y}\right)^{2}\right] \\
& \frac{B r}{(1-\phi)^{2.5}} \exp \left(-B V \theta_{i, j}\right) \\
& +\frac{B r \exp (-B V \theta)}{D a(1-\phi)^{2.5}}\left(\frac{K_{s}+2 K_{f}+\phi\left(K_{f}-K_{s}\right)}{K_{s}+2 K_{f}-2 \phi\left(K_{f}-K_{s}\right)}\right)_{i, j}{ }^{2}=0
\end{aligned}
$$

The corresponding discretized boundary conditions are

$$
\begin{aligned}
& w_{i, 0}=-w_{i, 1}, \theta_{i, 0}=-1-\theta_{i, 1}, \\
& w_{i, N y+1}=-w_{i, N y}, \theta_{i, N y+1}=1-\theta_{i, N y}, \\
& w_{0, j}=-w_{1 . j}, \theta_{0, j}=\theta_{1, j}, \\
& w_{N x+1, j}=-w_{N x, j}, \theta_{N x+1, j}=\theta_{N x, j}
\end{aligned}
$$


where $i$ and $j$ range from 1 to $N x$ and 1 to $N y$, respectively. $N x$ and $N y$ denote the number of grids inside the computational domain in the respective $x$ and $y$ directions. The values of $w_{i, j}$ and $\theta_{i, j}$, after setting the boundary conditions (17), are iterated until all the values of $w_{i, j}$ and $\theta_{i, j}$ in the grid system are less than a prescribed tolerance.

\subsection{Validation of the numerical code using grid independence study:}

A grid independence study is conducted using five different grid sizes of $11 \times 11,51 \times 51,101 \times 101,151 \times 151$ and $201 \times 201$ and the values of the average Nusslet number on the boundary $y=0$ is shown in Table-A1 with $B V=-0.5, G r=10, B r=1.0, D a=0.0001, I=2.0, \phi=0.02, A=1$ suing copper as nanoparticle and water as base fluid. Regular grid is used for all cases. It is observed from Table-1 that $101 \times 101$ grid compared with $151 \times 151$ and $201 \times 201$ does not have any significant effect on the results in terms of average Nusselt number. Therefore according to this observation, a uniform grid size of $101 \times 101$ is enough for this study.

Table-A1: Grid independent study

\begin{tabular}{|c|c|}
\hline Grid size & Average Nusselt number \\
\hline $11 \times 11$ & 0.530690080307085 \\
\hline $51 \times 51$ & 0.530681577489642 \\
\hline $101 \times 101$ & 0.530679728993398 \\
\hline $151 \times 151$ & 0.530679504025806 \\
\hline $201 \times 201$ & 0.530679458520223 \\
\hline
\end{tabular}

\section{Results and discussion}

The problem of heat transfer in a vertical rectangular duct filled with a nanofluid saturated with porous matrix is analysed for the viscosity dependent on the temperature. The governing equations which are coupled, nonlinear partial differential equations are solved using finite difference method of second order accuracy. The exponential dependence of the viscosity on the temperature is assumed and thermal conductivity is assumed to be constant. The Darcy-Brinkman-Forchhmier model is used to model the flow of the porous matrix. The effect of pertinent parameters such as nanoparticles, viscosity variation parameter $B V$, Darcy number $D a$, inertial parameter $I$, Grashof number $G r$, Brinkman number $B r$, solid volume fraction $\phi$ and aspect ratio $A$ on the velocity and temperature fields are shown pictorially. To understand the flow pattern in a more distinguishable form the pictures are shown in 3D (three dimension), 2D (two dimension) and 1D (one dimension) for all the parameters. The 1D graphs are drawn fixing the value of $y$ at 0.1 and varying $x$ from 0 to 1 .

The effect on the flow using different nanoparticle is shown in Figs. $2 \mathrm{a}$ and $2 \mathrm{~b}$ for different values of $B V$. It is seen from 3D graph as $B V$ increases flow gets enhanced in the upward direction $(y=1)$ for all the nanoparticles (Copper, Diamond and Titanium Oxide is taken in this study). This can also be justified by 2D graphs that the number of contours are dense in the lower region of the duct $(0<y<0.5)$ for negative values of $B V$ and in the upper region of the duct $(0.5<y<1)$ for positive values of the duct. The temperature field does not show any significant difference for different nanoparticles as seen in Fig. 2a. However Fig. $2 b$ tells that the optimum temperature is attained for Copper nanoparticle, and the minimum is obtained for Diamond nanoparticles for negative and positive values of $B V$. The velocity profiles are not much distorted for different nanoparticles for any of $B V$. The effect of using different nanaoparticles on the flow was the similar results obtained by Umavathi et al. (2015) for constant properties. The 1D graphs in Umavathi et al. (2015) are drawn at $y=0.5$ 
and hence the velocity profiles are in the upward direction whereas in this paper the velocity profiles are in the downward direction because the profiles are drawn at $y=0.1$.

The pictures from Figure 2 onwards are drawn using Copper nanoparticle cindering water as the base fluid. The effect of variable viscosity parameter $B V$ are shown in Figs. 3a and 3b. It is clear that as $B V$ increases flow increases in the upward direction (3D graphs). The velocity contours (2D graph) also show that the number of contours are dense in the lower region of the duct $(0<y<0.5)$ for negative values of $B V$, symmetric for $B V=0$ and dense in the upper region $(0.5<y<1)$ of the duct for positive value of $B V$ (Fig. 3a). The temperature filed is not much varied for the variations of $B V$. To understand the flow behavior in a more wider form, the 1D graphs are drawn choosing different points of $y$ varying $x$. The values of $y$ are chosen near the left wall, in the centre and near the right wall of the duct. One can visualize that the velocity profiles change their direction as $y$ moves from left to right of the duct. Near the left wall the profiles are in the downward direction, symmetric in the middle of the duct and in the upward direction of the duct. As $B V$ increases, flow increases in the downward direction for values of $B V<0$ and in the upward direction for $B V>0$. The profile for $B V=0$ lie above $B V<0$ and below $B V>0$. The temperature profiles show different nature when compared to velocity profiles. It is seen that the nature of $B V$ at $y=0.1$ and at $y=0.5$ are contradictory. That is to say that flow increases in the downward direction for $B V>0$ and in the upward direction for $B V<0$ at $y=0.1$ but its nature is converse at $y=0.5$ (Fig. 3b). Umavathi and Odelu (2015e) also observed the similar effect of $B V$ on the flow for regular, viscous fluid .

The effect of Darcy number $D a$ and $B V$ on the flow is shown in Figs. $4 \mathrm{a}$ and $4 \mathrm{~b}$. For fixed value of $B V$, the velocity curves are flat for small values of $D a$ and becomes narrow for large values of $D a$ and the contours are also flat for $D a=0.0001$ and becomes circular in nature for $D a=1.0$ whereas the temperature curves and contours does not show much variations as $D a$ increases (Fig. 4a). Here also the number of contours are dense in lower half of the duct for $B V<0$ and dense in the upper half region of the duct for $B V>0$. From Fig. $4 \mathrm{~b}$ it is clear that the velocity increases in the downward direction as $D a$ increases and temperature also increases as $D a$ increases. The nature of increase in $D a$ is to increase the flow is quite obvious because physically increase in $D a$ implies that porous matrix becomes more sparse.

The effect of inertial parameter $I$ on the flow is depicted in Figs. 5a and 5b. It is observed that the inertial parameter does not show much variations in the flow filed. But the effect of $B V$ show the similar nature as in Figs. $4 \mathrm{a}$ and $4 \mathrm{~b}$. That is to say that the contours are dense in the lower half region for $B V<0$ and dense in the upper region for $B V>0$ (Fig. 5b) and the profiles for $B V=0$ lie above $B V<0$ and below $B V>0$.

The effects of Grashof number, and Brinkman number along with $B V$ on the velocity and temperature fields are shown in Figs. 6a, 6b and 7a, 7b. As Grashof number and Brinkman number increases flow increases. Similar result was obtained by Umavathi and Odelu (20115b) for regular fluid in the absence of porous matrix and hence not more explanation is required.

The effect of solid volume fraction $\phi$ and $B V$ on the flow field is shown in Figs $8 \mathrm{a}$ and $8 \mathrm{~b}$. Here also it is seen that as $B V$ increases flow increases in the upward direction for both regular and also for nanofluid. The number of contours are dense in the lower half region for values of $B V<0$ and in the upper half region of the duct for values of $B V>0$. Here also the temperature contours are almost linear for any value of $\phi$ and $B V$ (Fig. 8a). However from 1D graph (Fig. 8b) one can infer that as $\phi$ increases velocity increases whereas temperature decreases for any value of $B V$.

The effect of aspect ratio $A$ on the flow is again the similar nature as obtained by Umavathi and Odelu (2015e). As the aspect ratio $A$ increases the profiles become wider. The effect of $B V$ remains the same as explained above for any value of $A$.

To understand the physical significance of the problem under study, the volumetric flow rate, skin friction and rate of heat transfer are evaluated and tabulated in Tables $1 \mathrm{a}, 1 \mathrm{~b}$ and $1 \mathrm{c}$ for the variations of the viscosity variation parameter $B V$. It is seen that the volumetric flow rate $Q$ increases as $B V$ increases for all the parameters. The volumetric flow rate is maximum for Silver nanoparticle and decreases for other nanoparticles. As Darcy number, Grashof number, Brinkman number and aspect ratio $A$ increases the volumetric flow rate increases whereas it decreases as inertial parameter and solid 
volume fraction increases. The shear stress $\frac{d w}{d y}$ increases as $B V$ decreases in magnitude at $y=0$ and increases at $y=1$ for all the nanoparticles and the maximum is attained for Silver nanoparticle both at $y=0$ and at $y=1$. The shear stress $\frac{d w}{d y}$ at $y=0$ and at $y=1$ increases as $D a, G r$ and $A$ increases. As $\phi$ and $B r$ increases the shear stress $\frac{d w}{d y}$ decreases at $y=0$ and increases at $y=1$ (Table 1a). The shear stress $\frac{d w}{d x}$ at $x=0$ and at $x=1$ also increases as $B V$ increases. It decreases at $x=0$ and at $x=1$ for all the nanoparticles when compared with Silver nanoparticle. As $D a, G r, B r$ and $A$ increases $\frac{d w}{d x}$ at $x=0$ and at $x=1$ also increases, but decreases with $I$ and $\phi$ (Table $1 \mathrm{~b}$ ) The rate of heat transfer $\frac{d \theta}{d y}$ at $y=0$ and at $y=1$ decreases slightly as $B V$ increases for all the governing parameters. The rate of heat transfer decreases at $y=0$ and increases at $y=1$ for all the nanoparticles when compared with Silver nanoparticle. As $D a, G r, B r$ and $A$ increases, the rate of heat transfer increases at $y=0$ and decreases at $y=1$ whereas reversal effect is observed for the inertial parameter $I$. The rate of heat transfer increases both at $y=0$ and at $y=1$ as solid volume fraction $\phi$ increases.
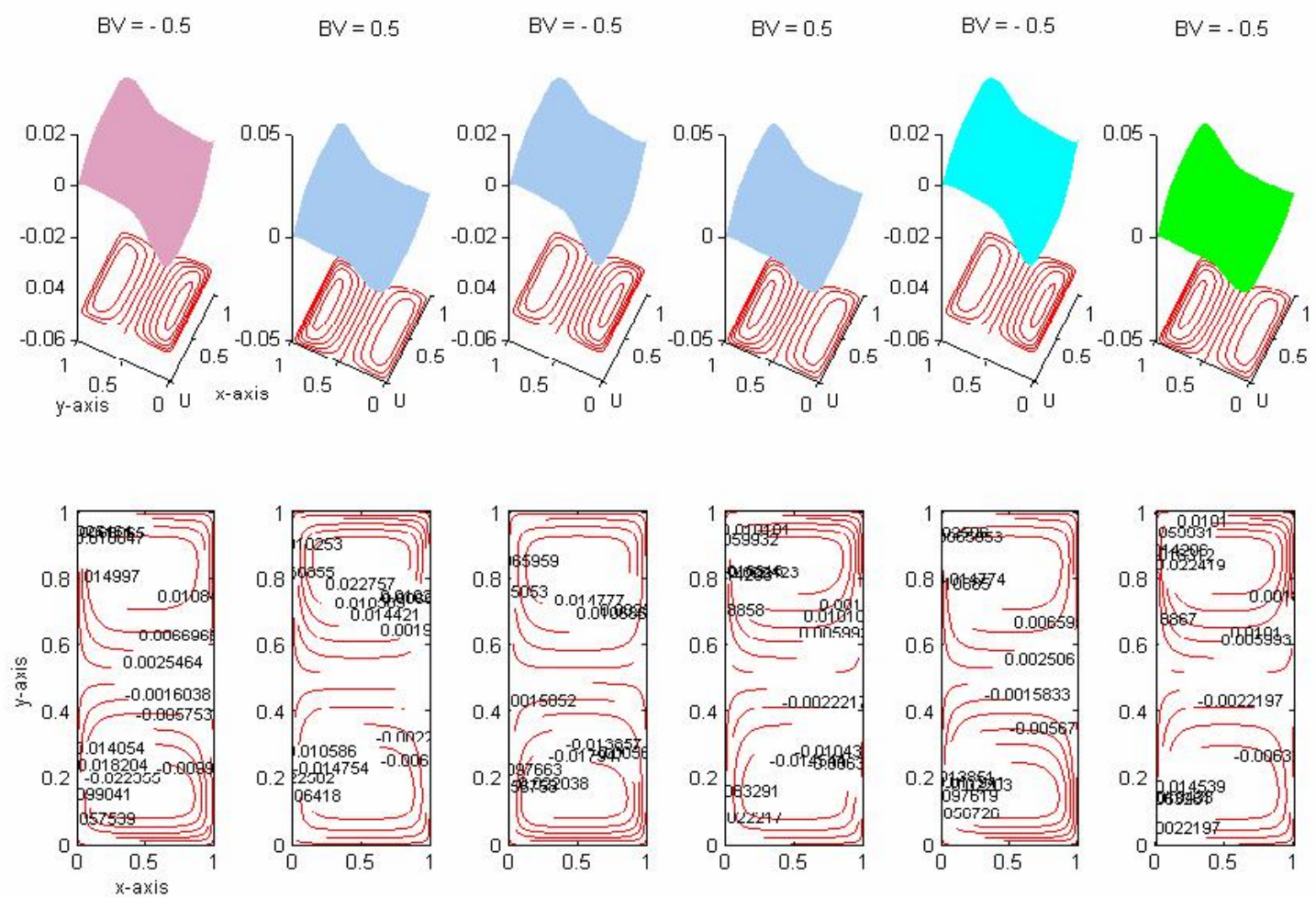

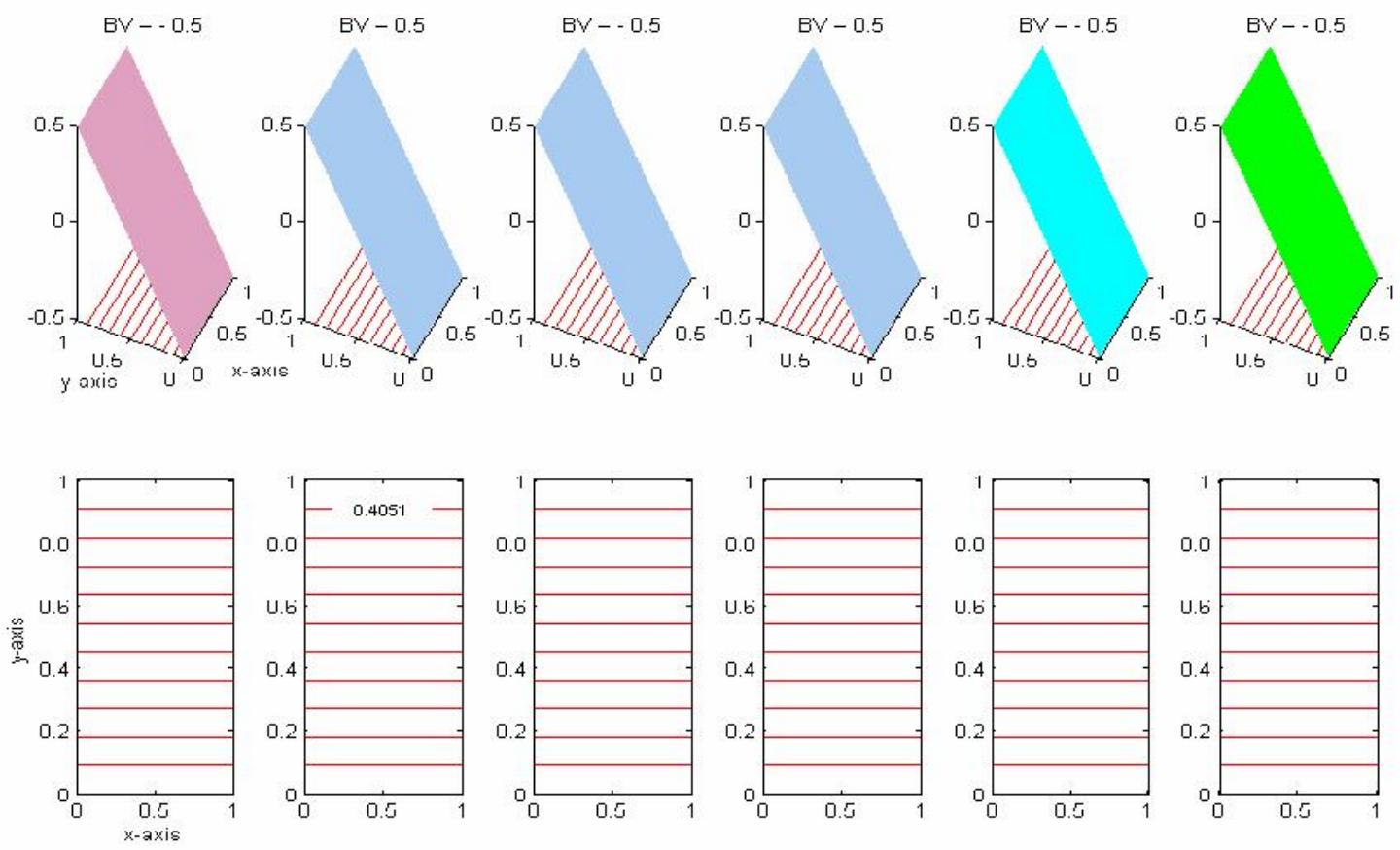

Figure 2a: Velocity and temperature contours for Copper, Diamond and Titanium Oxide nanoparticles from left to right respectively with $D a=0.01, I=2, G r=10, B r=1, \phi=0.02, A=1$ for $B V= \pm 0.5$
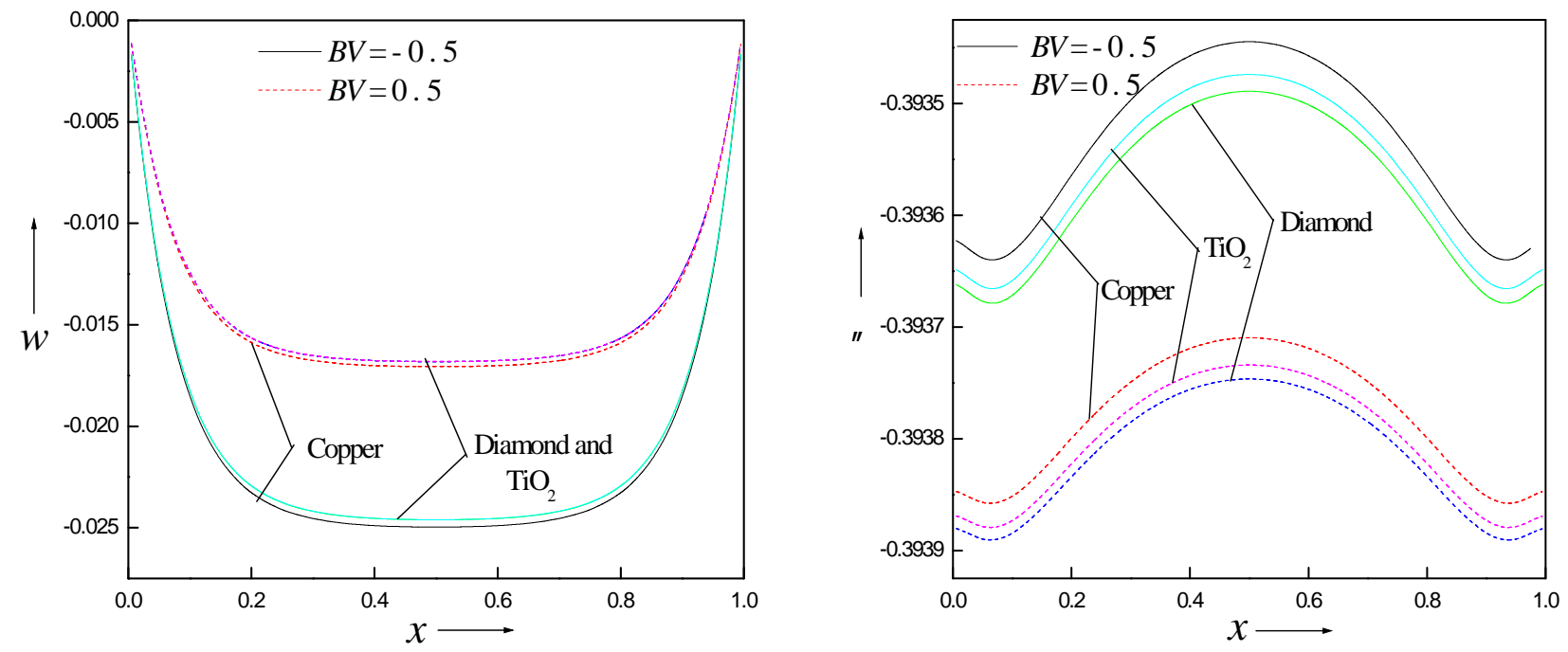

Figure 2b: Velocity and temperature profiles for Copper, Diamond and Titanium Oxide nanoparticles with $D a=0.01, I=2, G r=10, B r=1, \phi=0.02, A=1$ at $y=0.1$ for $B V= \pm 0.5$ 

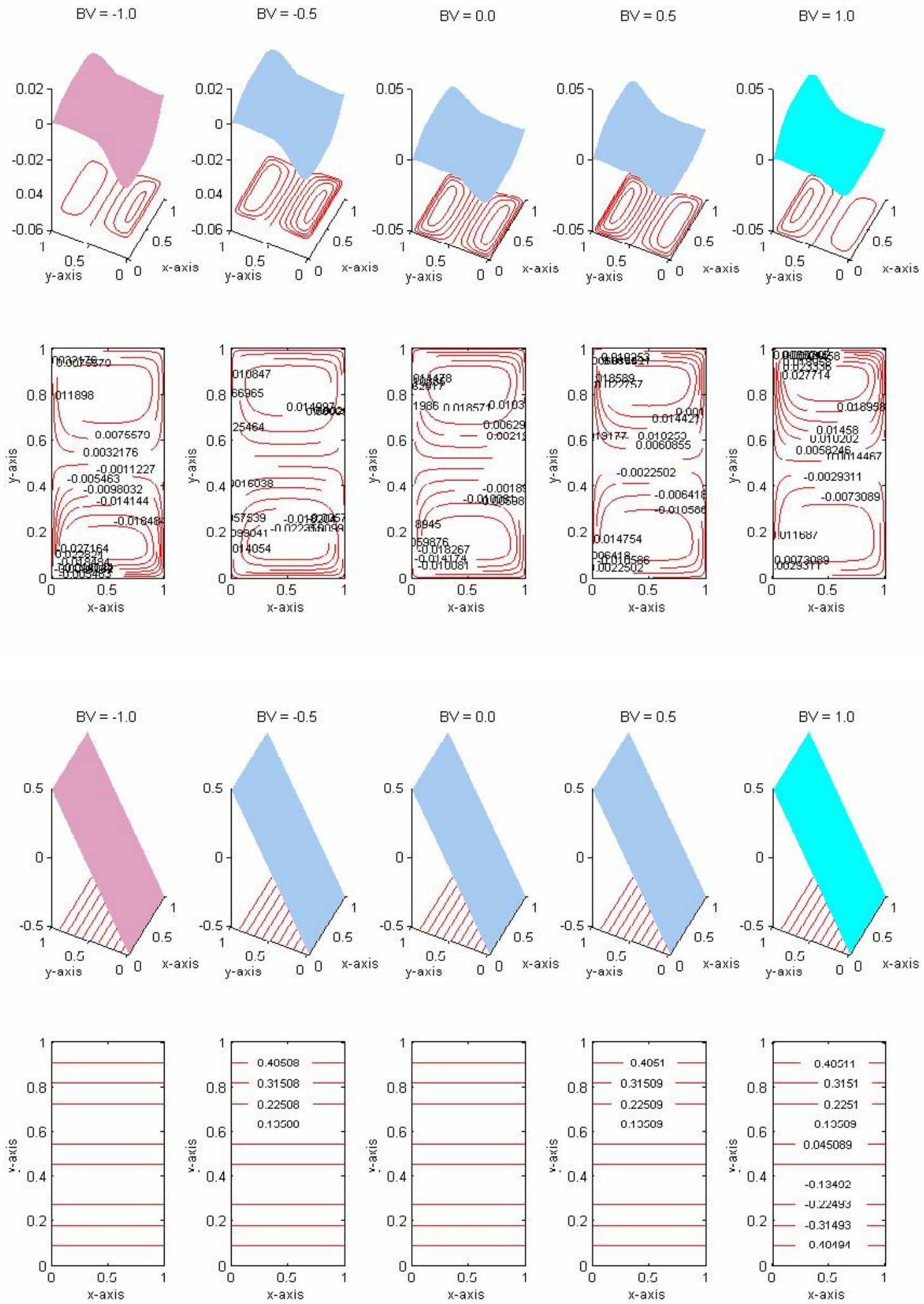

Figure 3a: Velocity and temperature contours for different values of $B V$ with $D a=0.01, I=2, G r=10, B r=1, \phi=0.02, A=1$ 

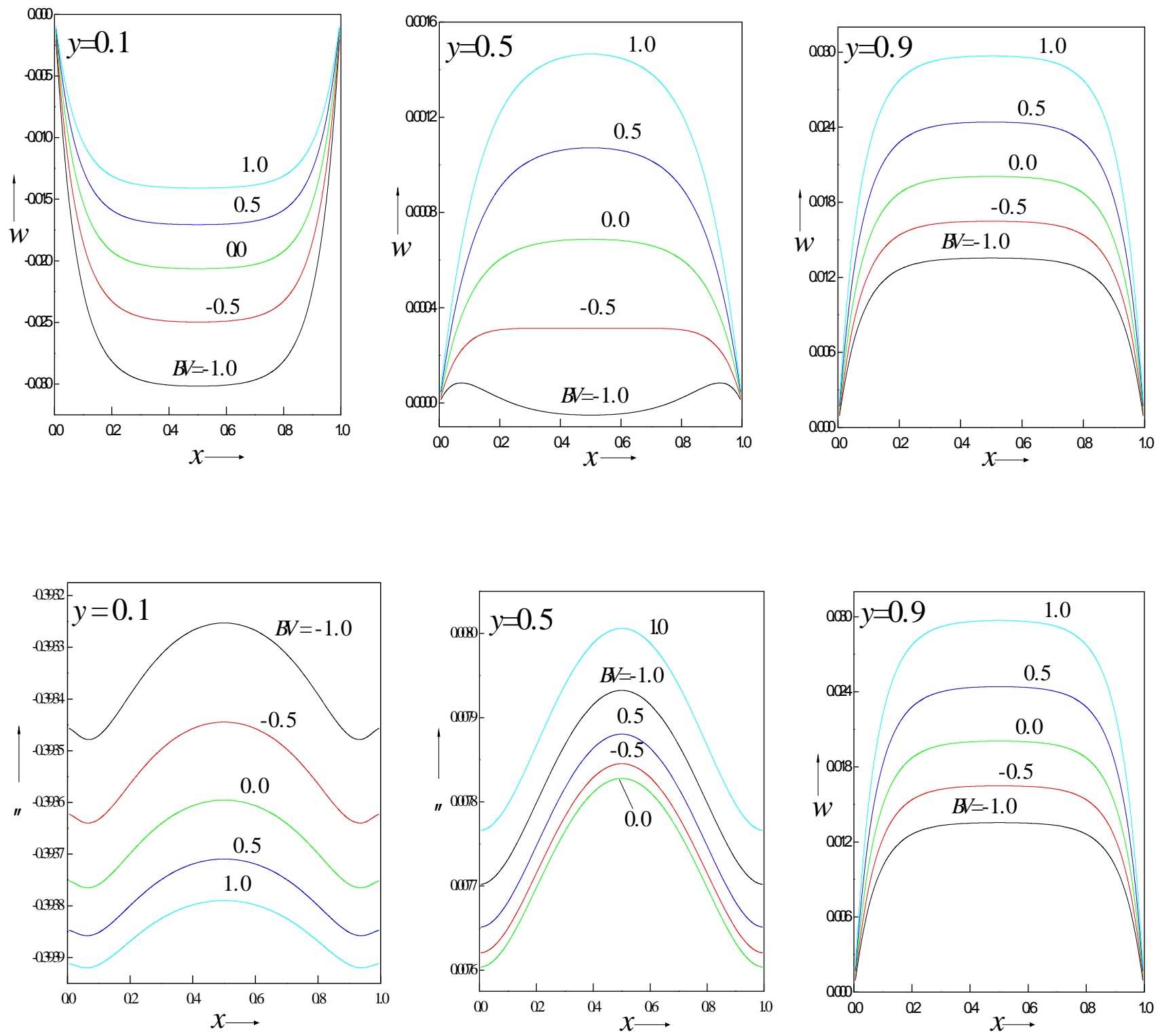

Figure 3b: Velocity and temperature profiles for different values of $B V$ with $D a=0.01, I=2, G r=10, B r=1, \phi=0.02, A=1$ at $y=0.1,0.5,0.9$ 

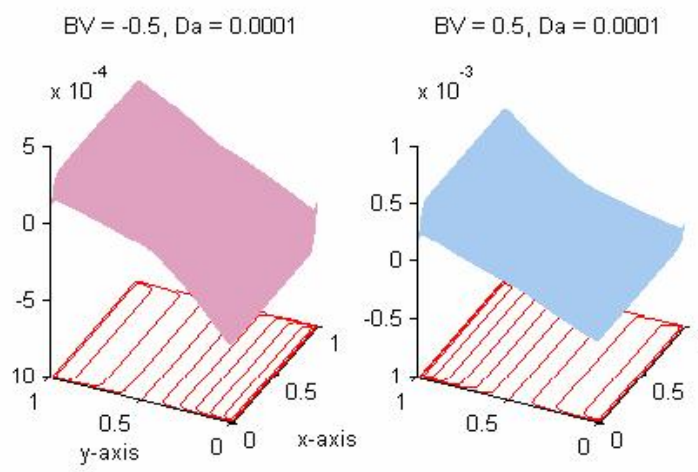

$B V=-0.5, D a=1.0$

$\mathrm{BV}=0.5, \mathrm{Da}=1.0$
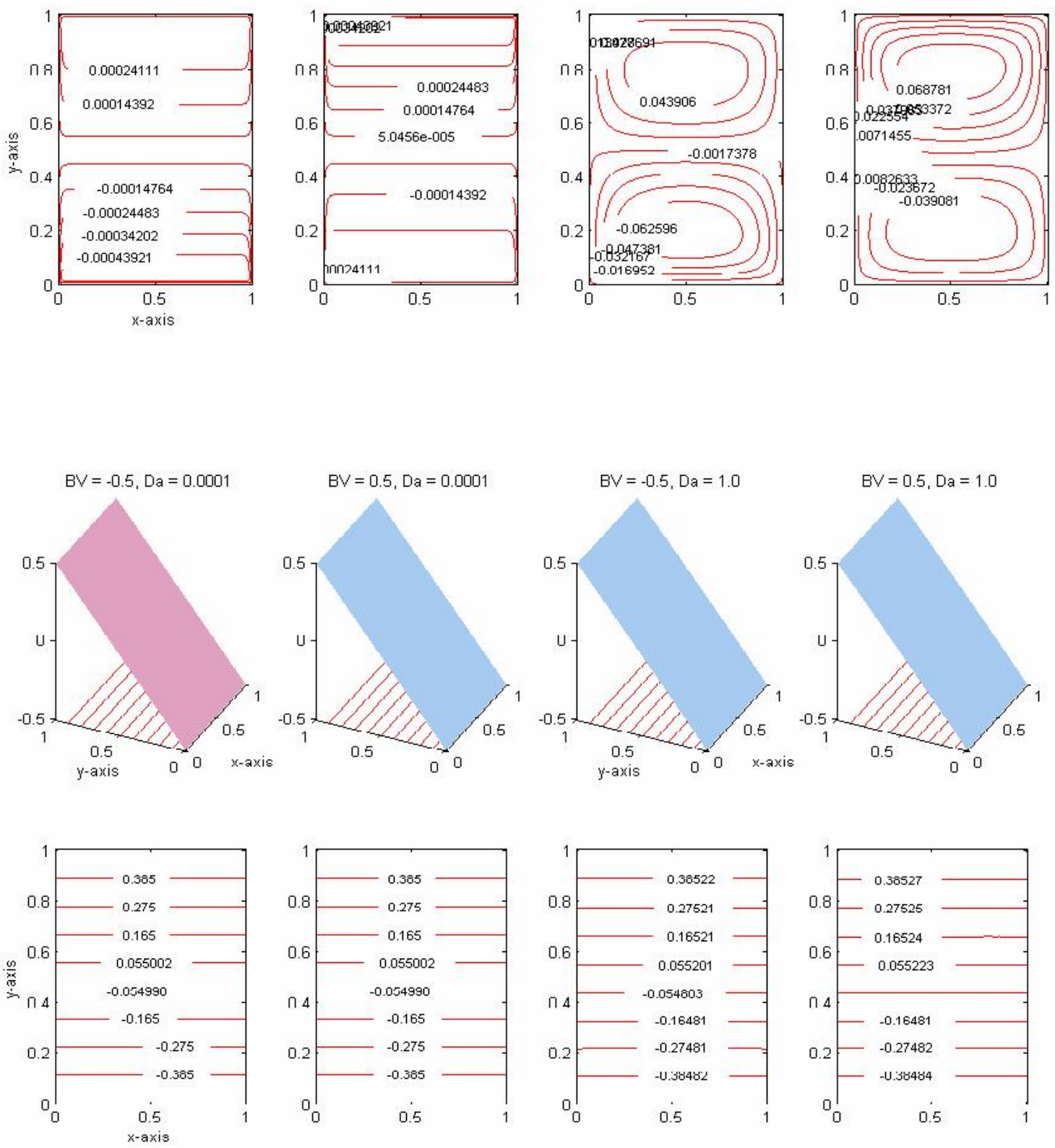
Figure 4a: Velocity and temperature contours for different values of $B V$ and $D a$ with $I=2, G r=10, B r=1, \phi=0.02, A=1$
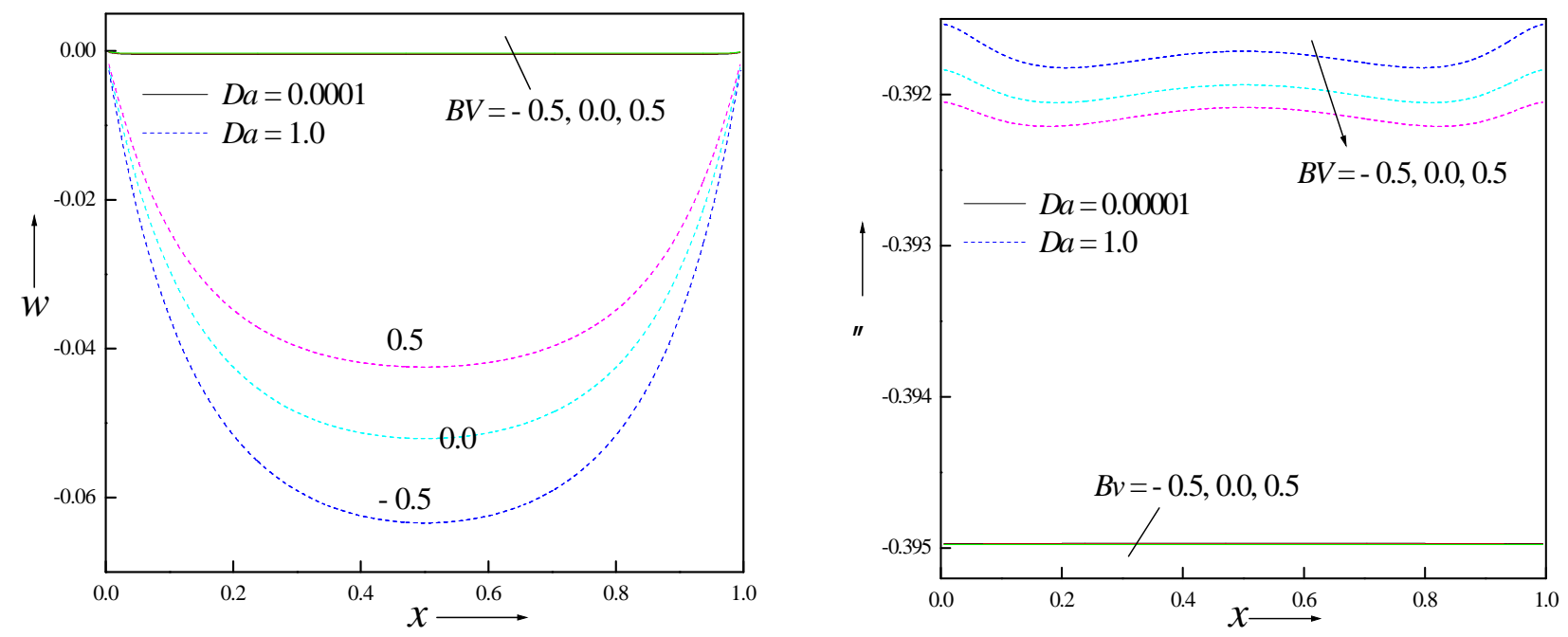

Figure 4b: Velocity and temperature profiles for different values of $B V$ and $D a$ with $I=2, G r=10, B r=1, \phi=0.02, A=1$ at $y=0.1$
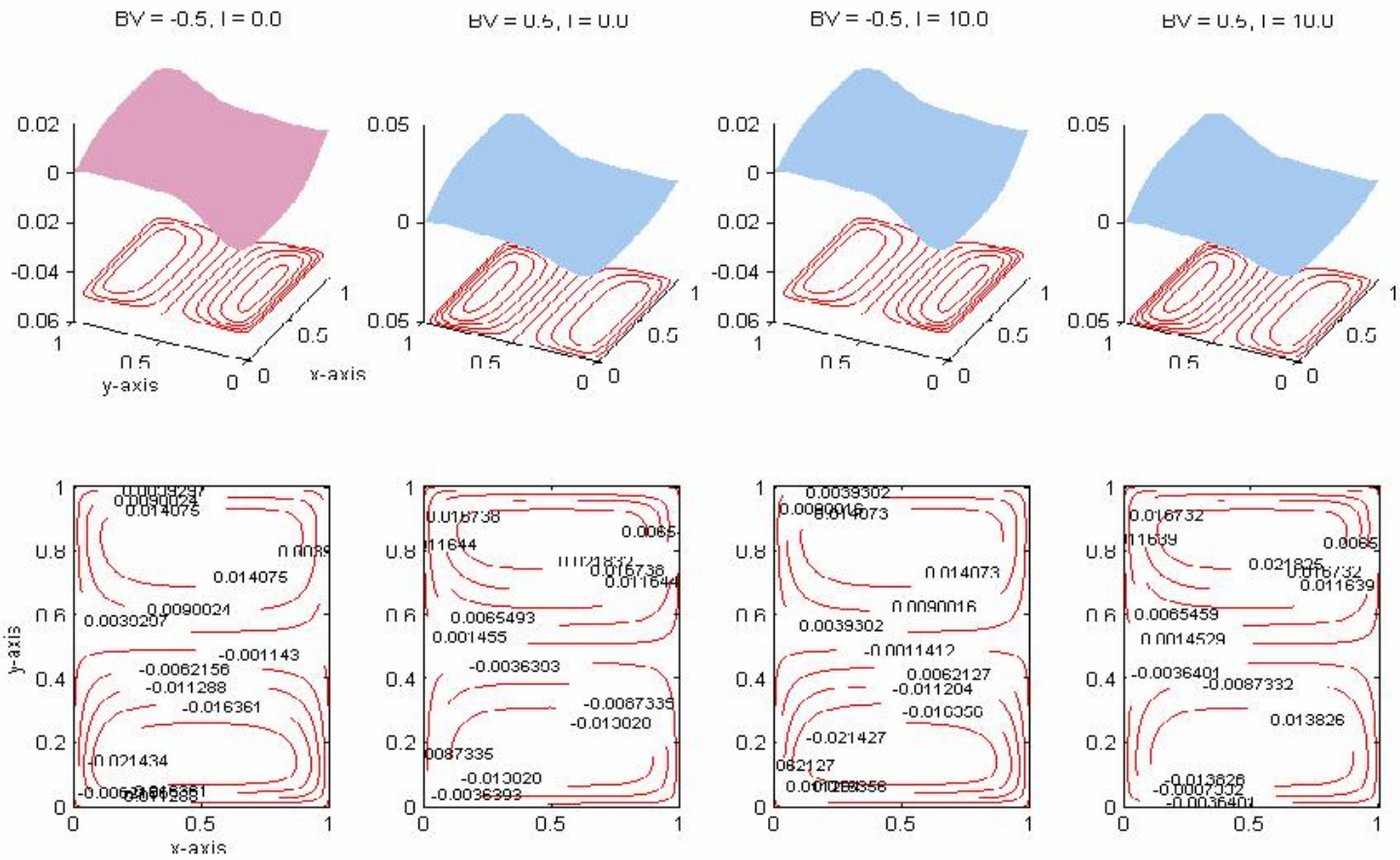

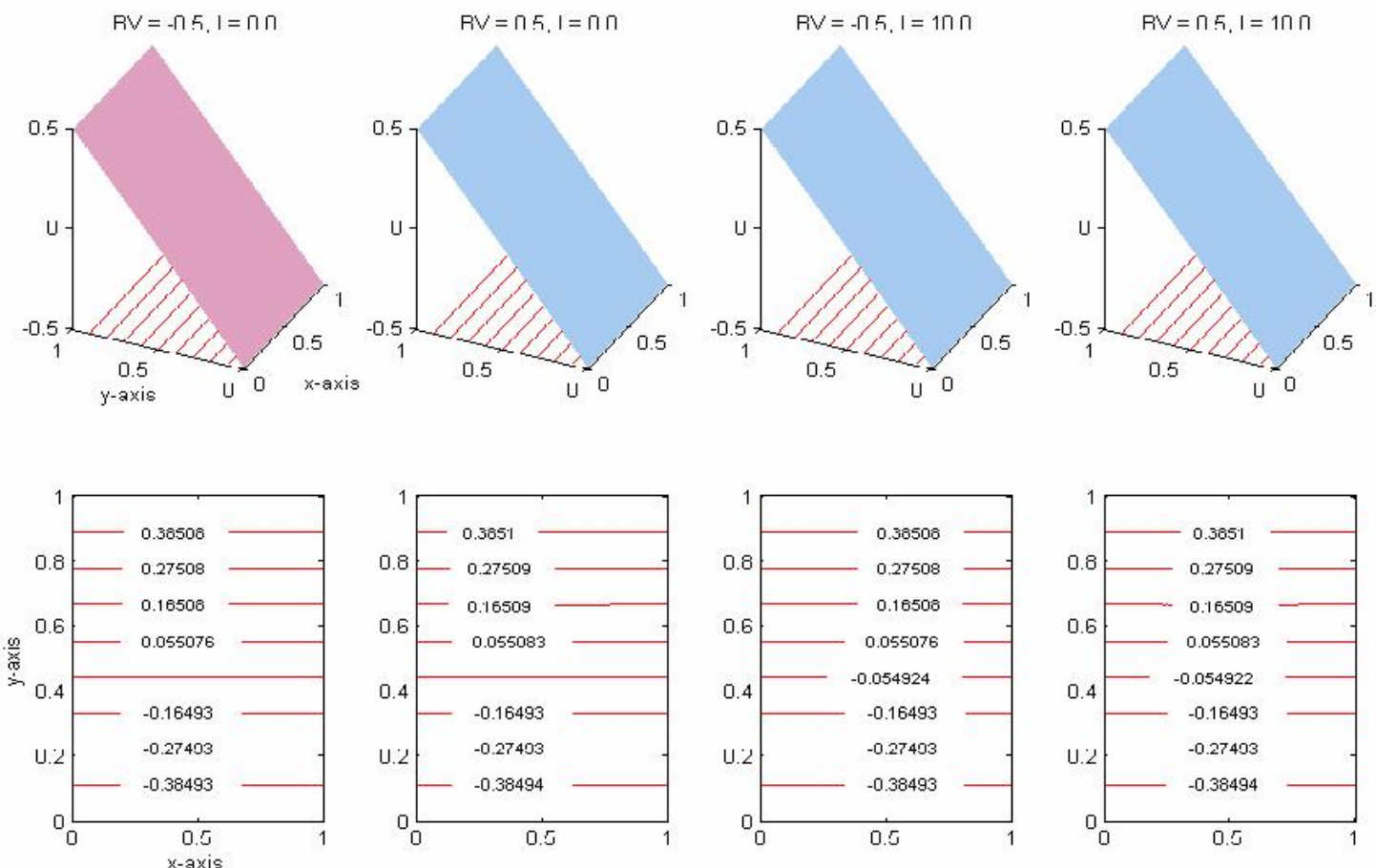

Figure 5a: Velocity and temperature contours for different values of $B V$ and $I$ with $D a=0.01, G r=10, B r=1, \phi=0.02, A=1$
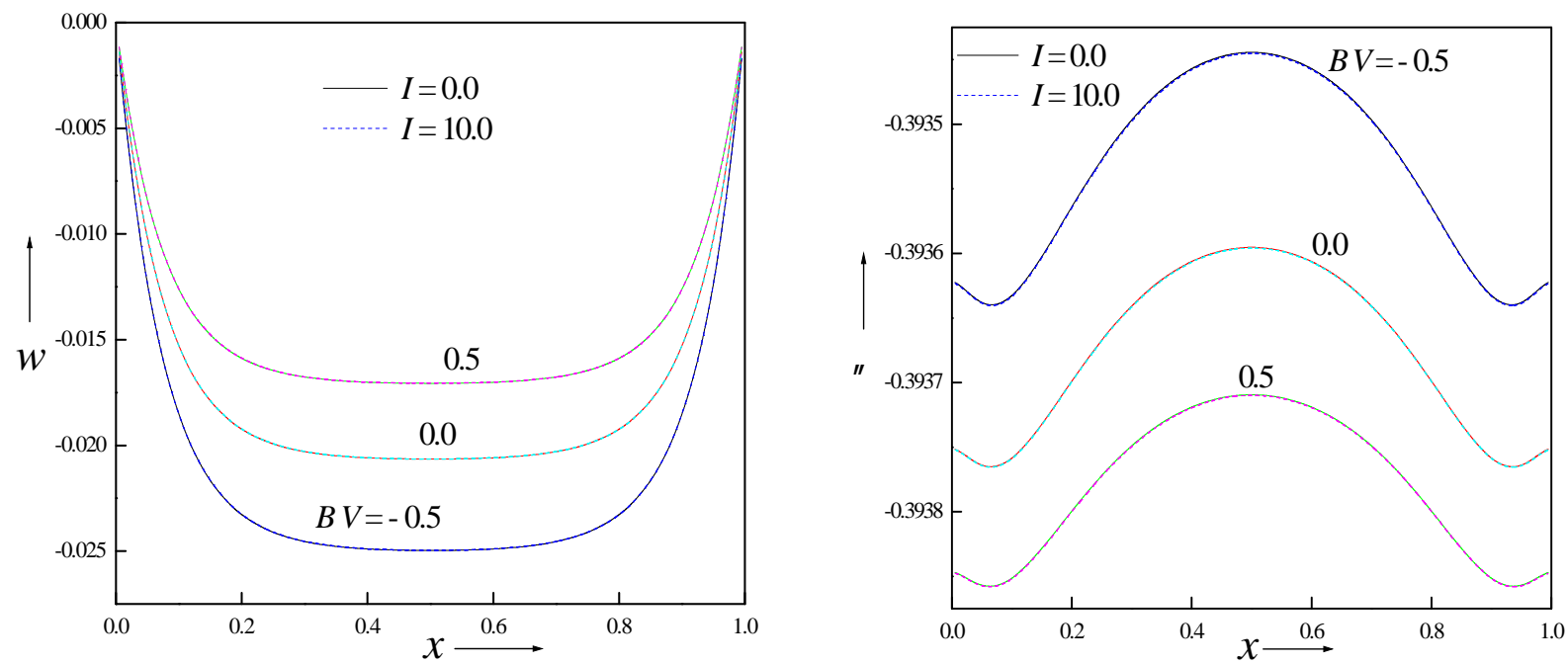

Figure 5b: Velocity and temperature profiles for different values of $B V$ and $I$ with $D a=0.01, G r=10, B r=1, \phi=0.02, A=1$ at $y=0.1$ 

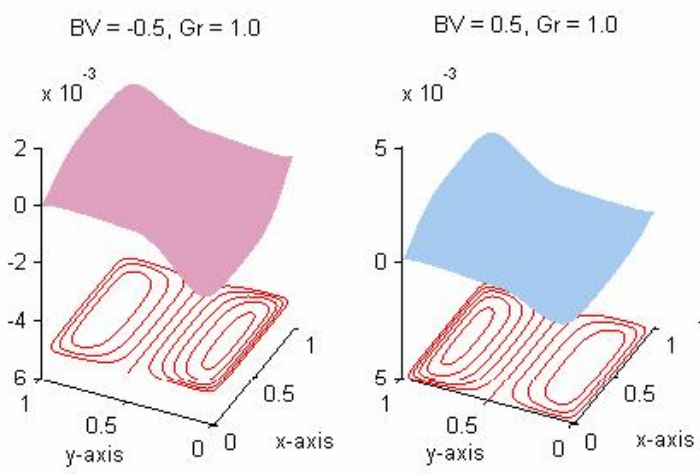

$\mathrm{BV}=-0.5, \mathrm{Gr}=25.0$

$\mathrm{BV}=0.5, \mathrm{Gr}=25.0$
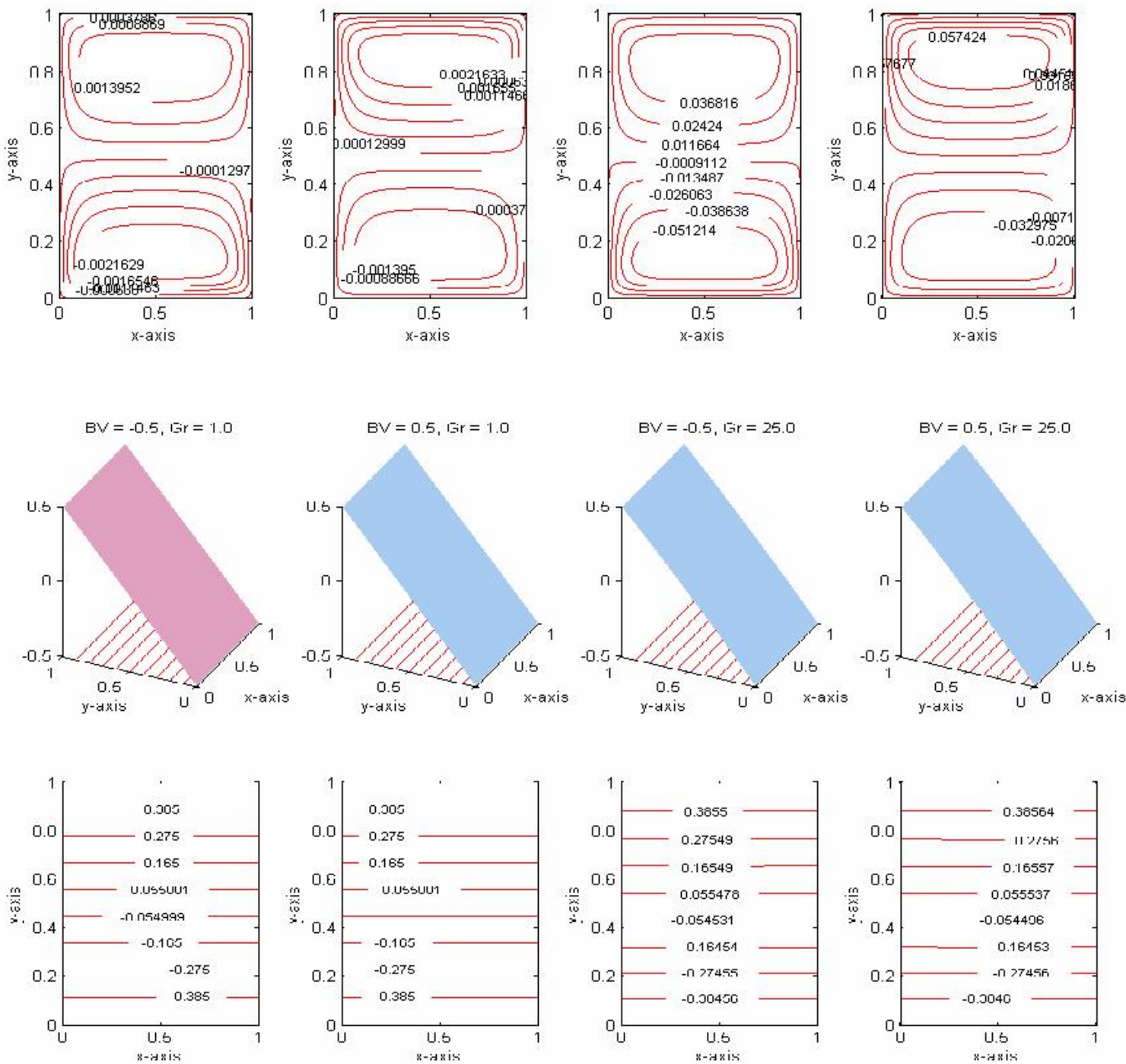

Figure 6a: Velocity and temperature contours for different values of $B V$ and $G r$ with $D a=0.01, I=2, B r=1, \phi=0.02, A=1$ 

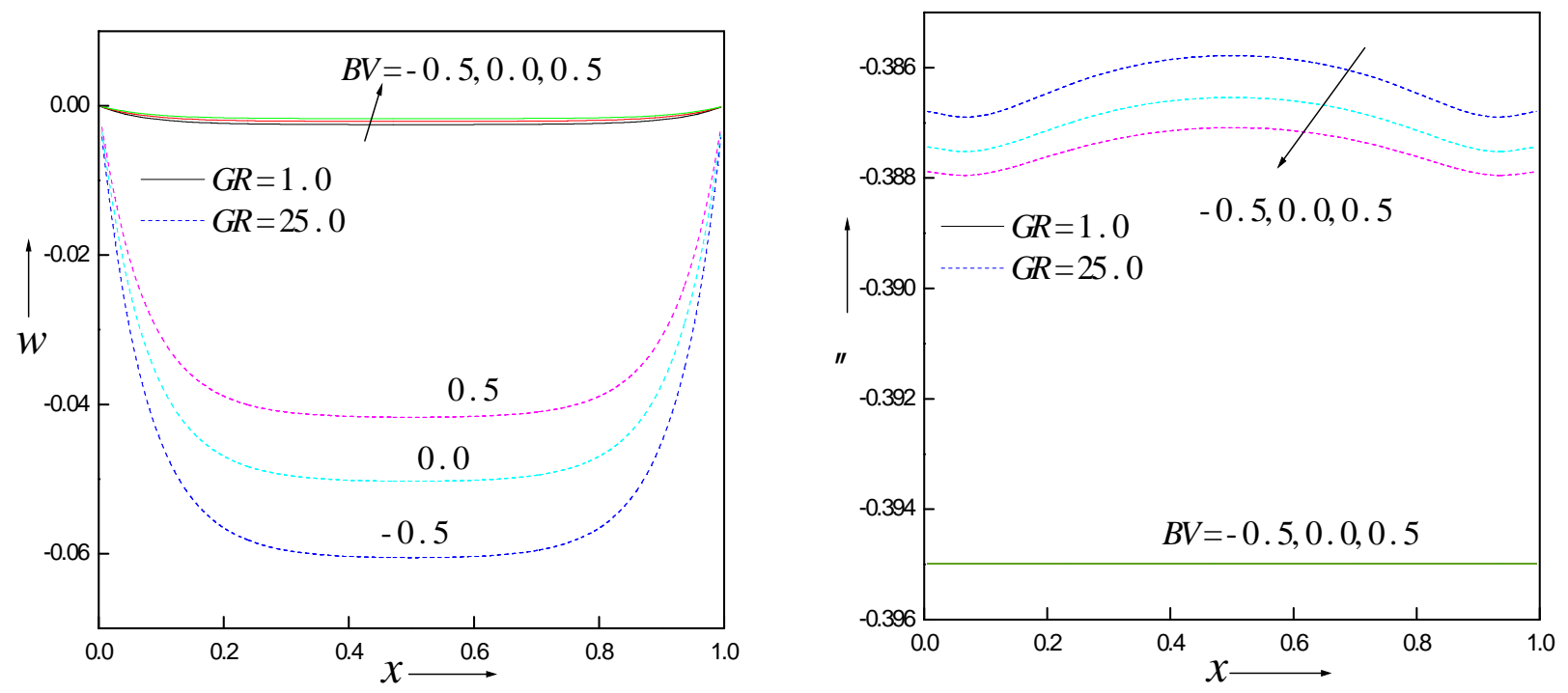

Figure 6b: Velocity and temperature profiles for different values of $B V$ and $G r$ with $D a=0.01, I=2, B r=1, \phi=0.02, A=1$ at $y=0.1$
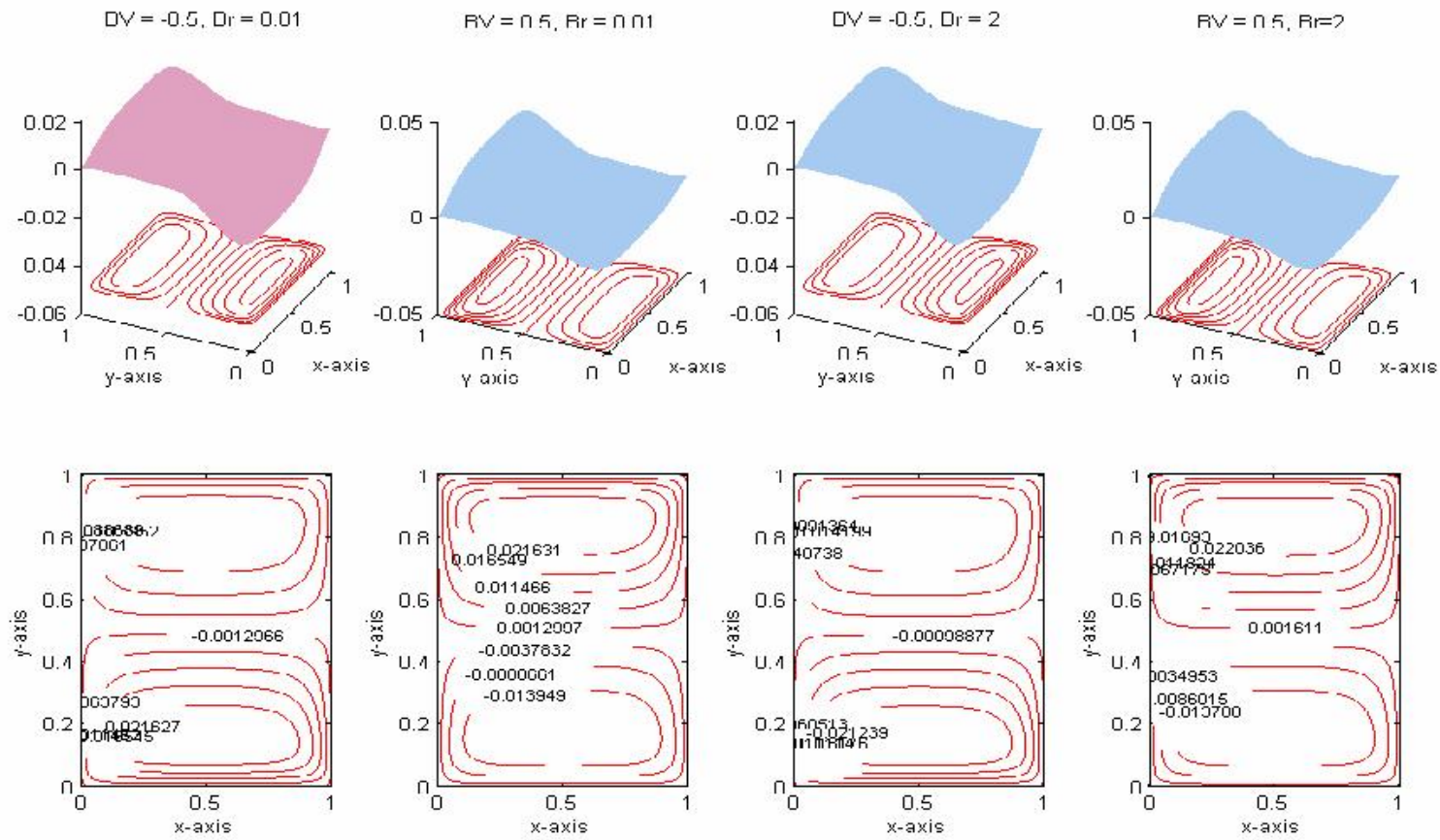

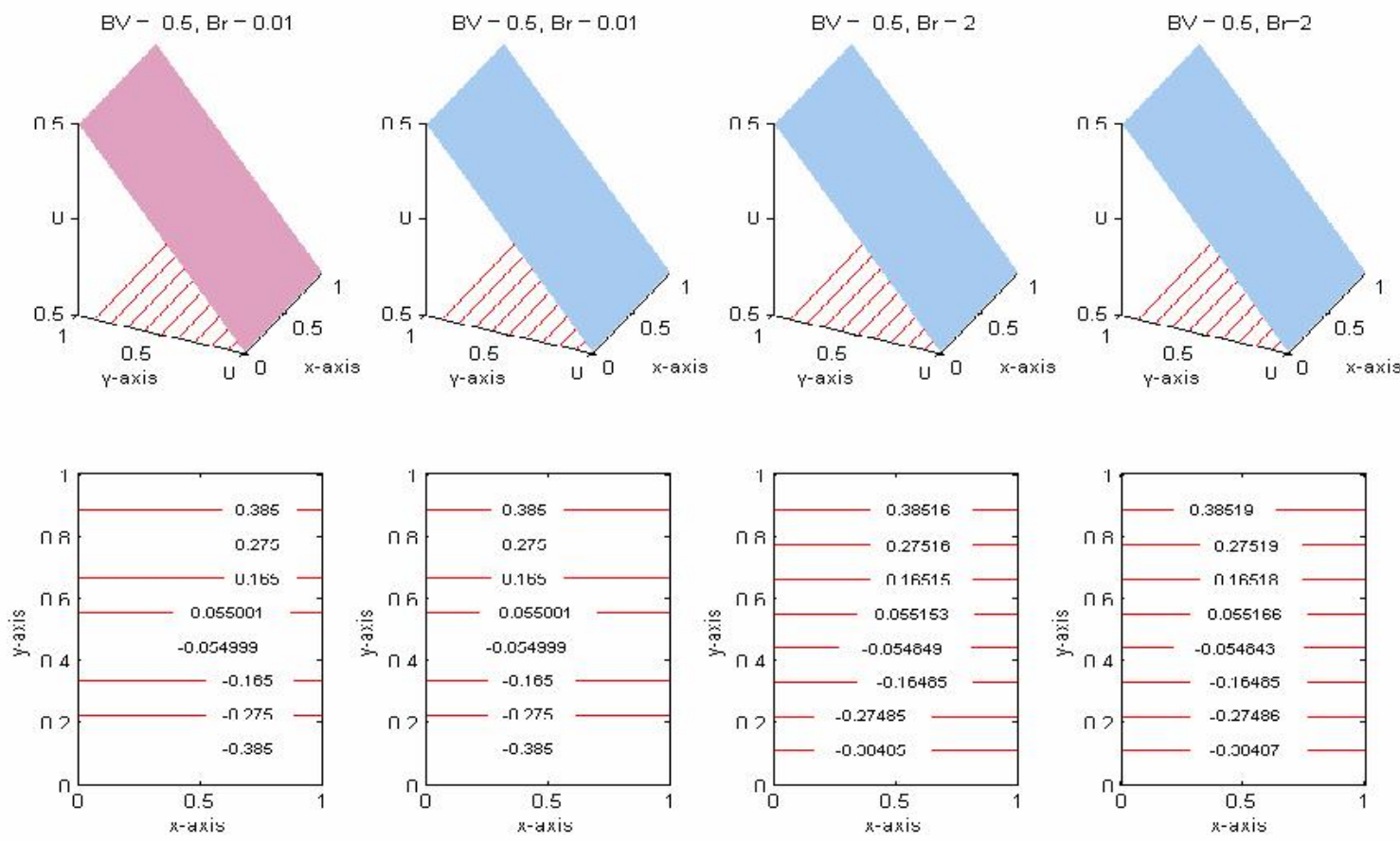

Figure 7a: Velocity and temperature contours for different values of $B V \quad$ and $B r \quad$ with $D a=0.01, I=2, G r=10, \phi=0.02, A=1$
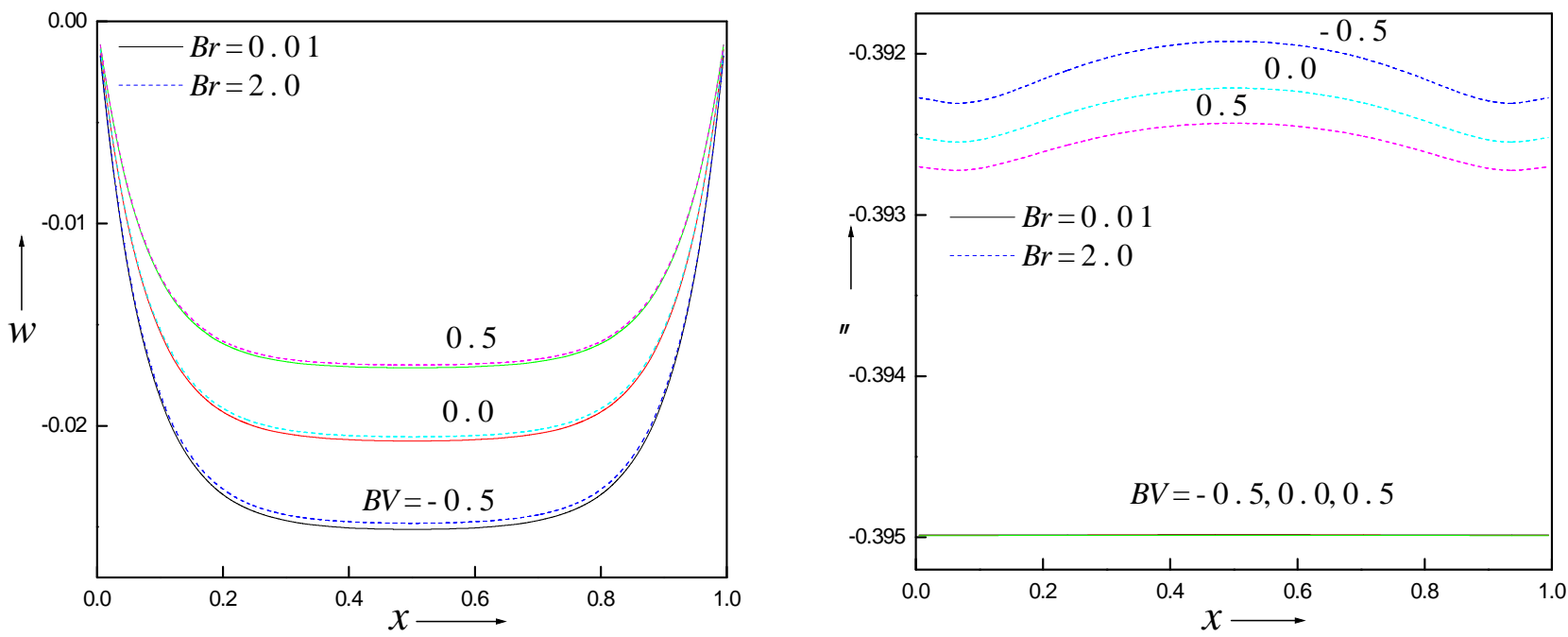

Figure 7b: Velocity and temperature profiles for different values of $B V \quad$ and $B r \quad$ with $D a=0.01, I=2, G r=10, \phi=0.02, A=1$ at $y=0.1$ 

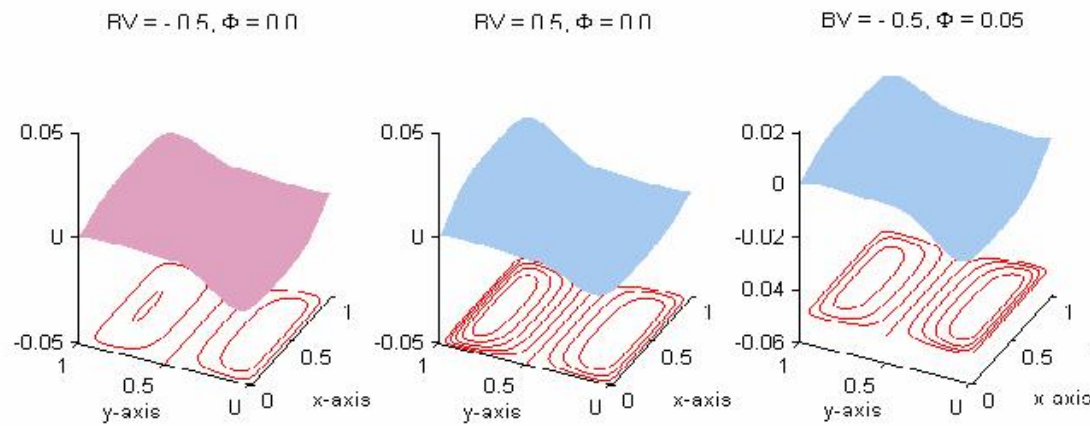

$R \vee=\cap 5, \Phi=\cap ก 5$
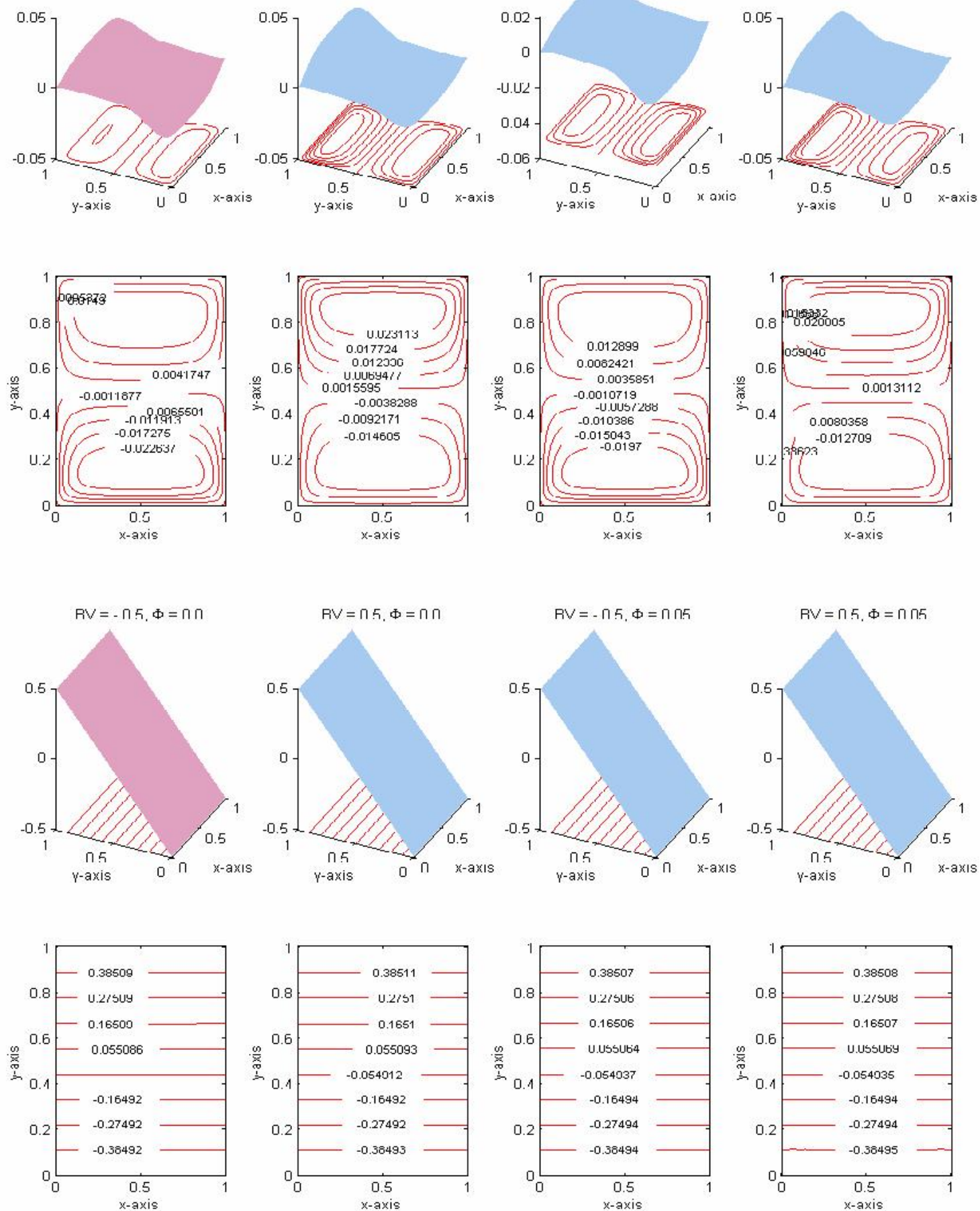

Figure 8a: Velocity and temperature contours for different values $D a=0.01, I=2, G r=10, B r=1, A=1$

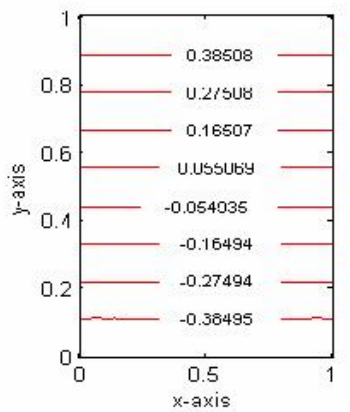



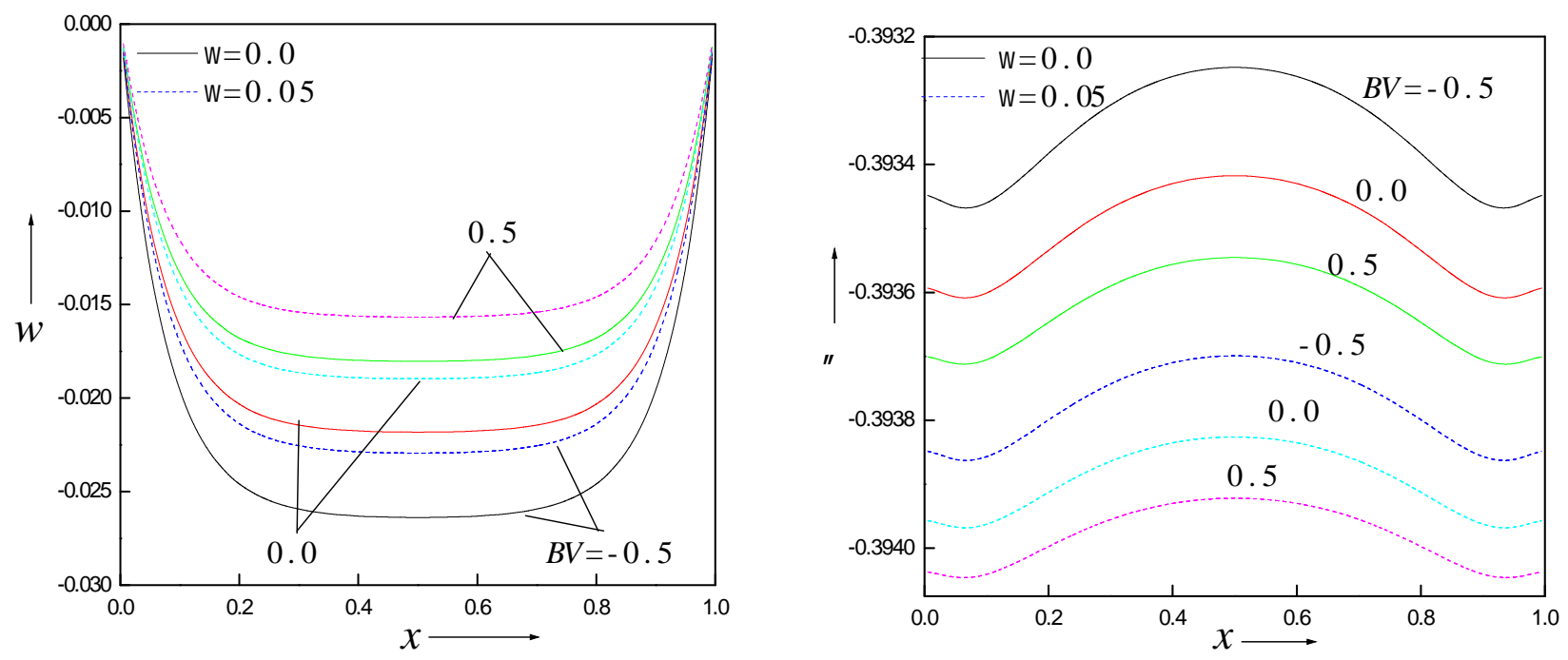

Figure 8b: Velocity and temperature profiles for different values of $B V$ and $\phi$ with $D a=0.01, I=2, G r=10, B r=1, A=1$ at $y=0.1$
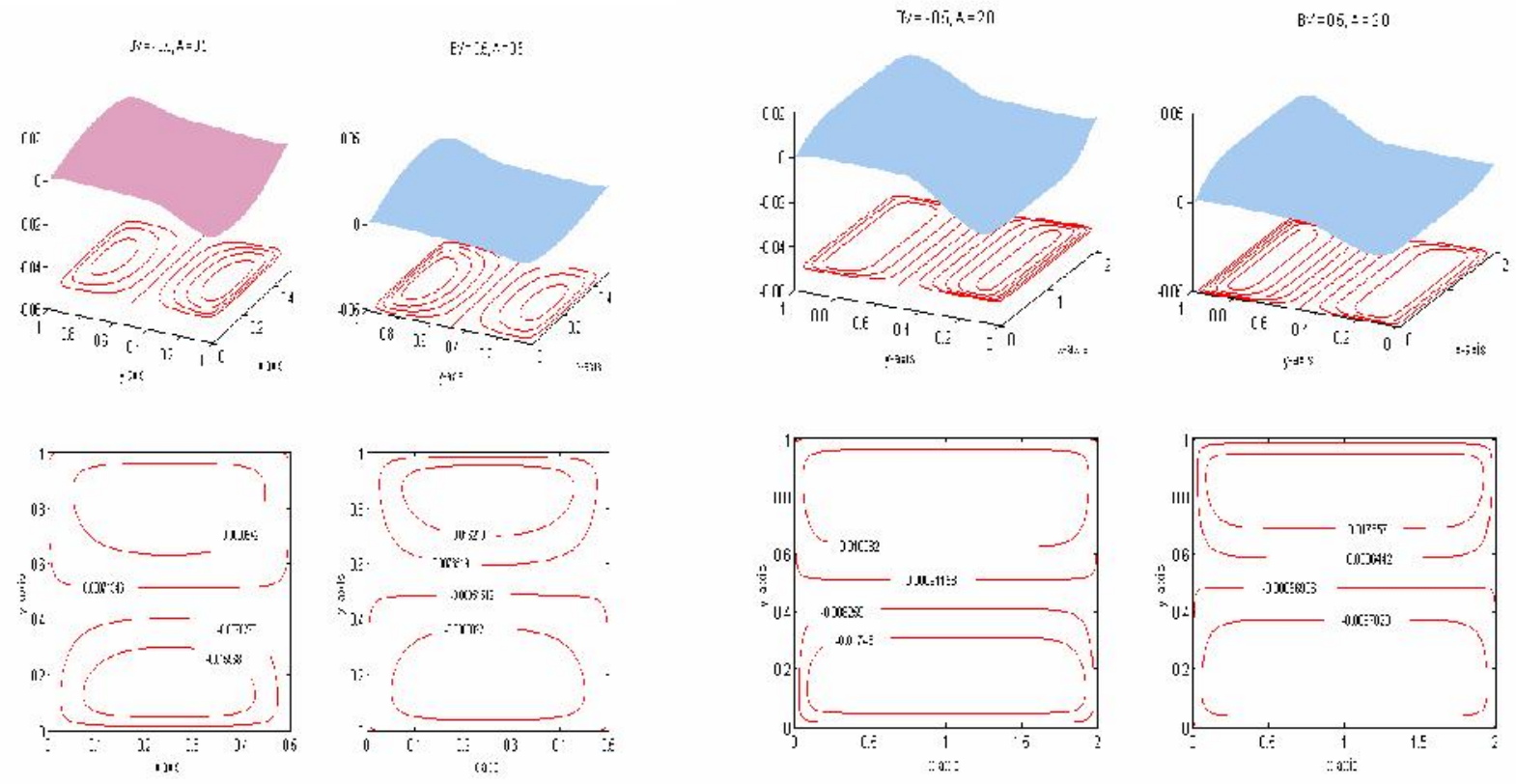

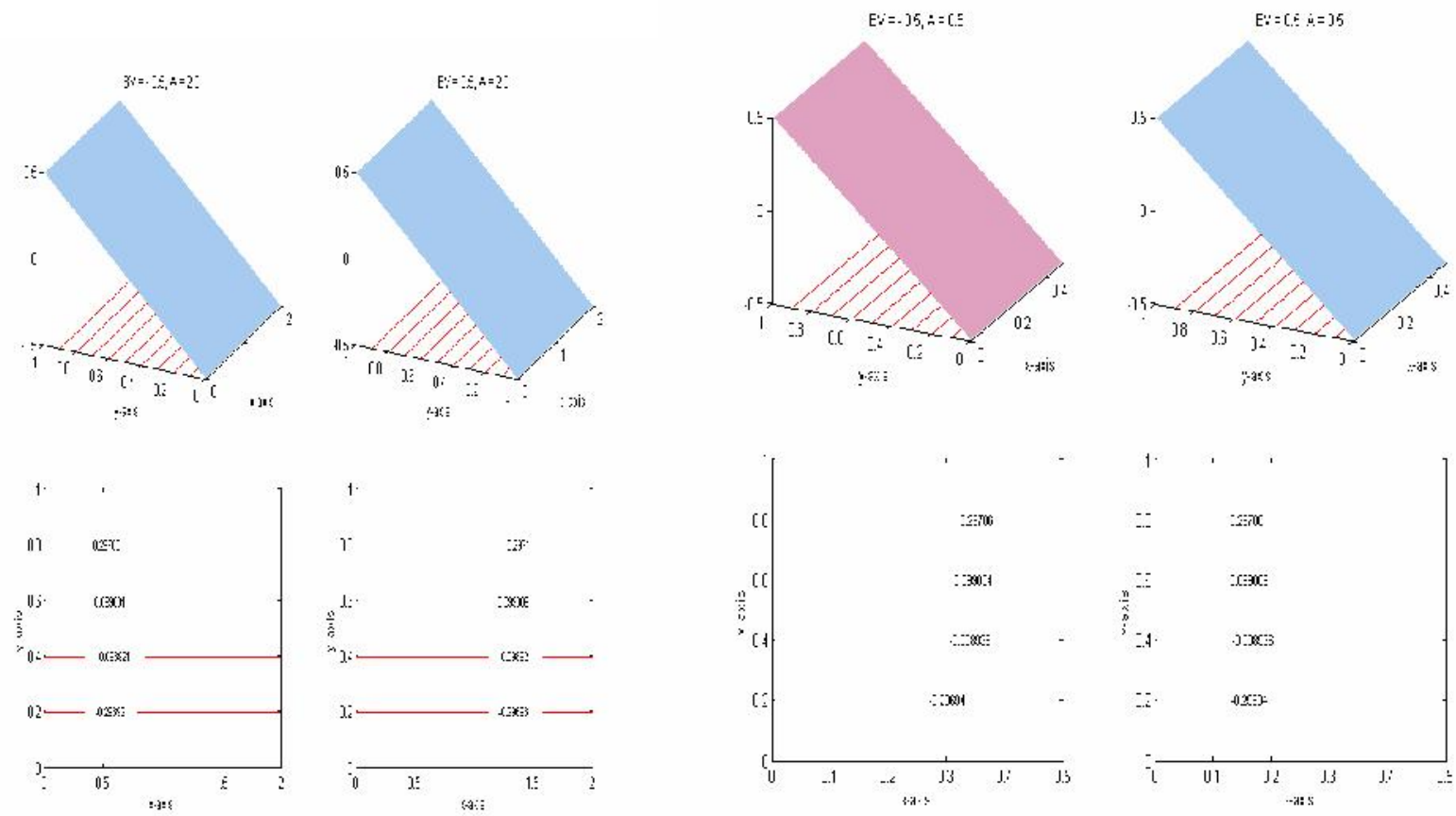

Figure 9a: Velocity and temperature contours for different values of $B V$ and $A$ with $D a=0.01, I=2, G r=10, B r=1, \phi=0.02$ 

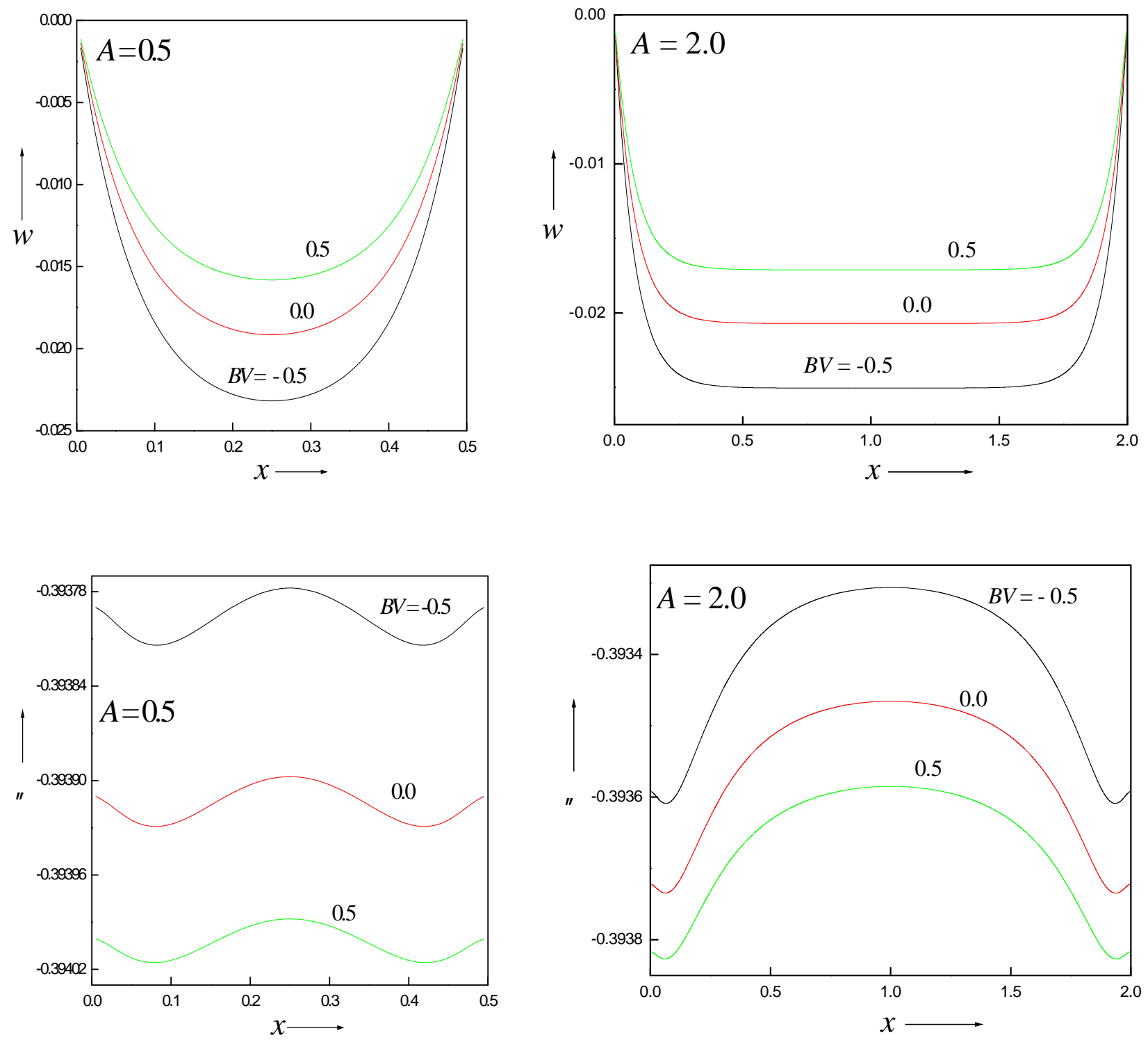

Figure 9b: Velocity and temperature profiles for different values of $B V$ and $A$ with $D a=0.01, I=2, G r=10, B r=1, \phi=0.02$ at $y=0.1$

Table 1a. Values of volumetric flow rate and skin friction with $D a=0.01, I=2, G r=10, B r=1, \phi=0.02, A=1$

\begin{tabular}{|l|l|l|l|l|l|l|}
\hline$B V$ & $Q$ & $\left.\frac{d w}{d y}\right|_{y=0}$ & $\left.\frac{d w}{d y}\right|_{y=1}$ & $Q$ & $\left.\frac{d w}{d y}\right|_{y=0}$ & $\left.\frac{d w}{d y}\right|_{y=1}$ \\
\cline { 2 - 7 } & $C u$ & & & & \\
\hline-0.5 & $-1.690 \mathrm{E}-3$ & -0.222558 & -0.147861 & $-1.668 \mathrm{E}-3$ & -0.219296 & -0.145679 \\
\hline 0.0 & $1.397 \mathrm{E}-4$ & -0.176508 & -0.186592 & $1.350 \mathrm{E}-4$ & -0.173919 & -0.183837 \\
\hline 0.5 & $1.981 \mathrm{E}-3$ & -0.139953 & -0.235456 & $1.949 \mathrm{E}-3$ & -0.137900 & -0.231979 \\
\hline
\end{tabular}


Table 1a (cont'd). Values of volumetric flow rate and skin friction with $D a=0.01, I=2, G r=10, B r=1, \phi=0.02, A=1$

\begin{tabular}{|c|c|c|c|c|c|c|}
\hline \multirow[t]{3}{*}{$B V$} & $Q$ & $\left.\frac{d w}{d y}\right|_{y=0}$ & $\left.\frac{d w}{d y}\right|_{y=1}$ & $Q$ & $\left.\frac{d w}{d y}\right|_{y=0}$ & $\frac{d w}{d y}$ \\
\hline & \multicolumn{3}{|l|}{$\mathrm{Cu}$} & \multicolumn{3}{|l|}{$\mathrm{TiO}_{2}$} \\
\hline & \multicolumn{3}{|l|}{ Silver } & \multicolumn{3}{|l|}{ Diamond } \\
\hline-0.5 & $-1.695 \mathrm{E}-3$ & -0.223358 & -0.148398 & $-1.670 \mathrm{E}-3$ & -0.219363 & -0.145716 \\
\hline 0.0 & $1.412 \mathrm{E}-4$ & -0.177143 & -0.187270 & $1.337 \mathrm{E}-4$ & -0.173972 & -0.183884 \\
\hline \multirow[t]{2}{*}{0.5} & $1.989 \mathrm{E}-3$ & -0.140457 & -0.236312 & $1.948 \mathrm{E}-3$ & -0.137941 & -0.232037 \\
\hline & \multicolumn{3}{|c|}{$D a=0.0001$} & \multicolumn{3}{|l|}{$D a=1$} \\
\hline-0.5 & $-3.689 \mathrm{E}-5$ & $-2.748 \mathrm{E}-2$ & $-1.765 \mathrm{E}-2$ & $-4.465 \mathrm{E}-3$ & -0.389199 & -0.266593 \\
\hline 0.0 & $3.339 \mathrm{E}-8$ & $-2.147 \mathrm{E}-2$ & $-2.258 \mathrm{E}-2$ & $1.939 \mathrm{E}-3$ & -0.309393 & -0.336435 \\
\hline \multirow[t]{2}{*}{0.5} & $3.696 \mathrm{E}-5$ & $-1.678 \mathrm{E}-2$ & $-2.890 \mathrm{E}-2$ & $8.449 \mathrm{E}-3$ & -0.245045 & -0.423479 \\
\hline & \multicolumn{3}{|l|}{$I=0.0$} & \multicolumn{3}{|l|}{$I=10.0$} \\
\hline-0.5 & $-1.691 \mathrm{E}-3$ & -0.222564 & -0.147863 & $-1.690 \mathrm{E}-3$ & -0.222536 & -0.147854 \\
\hline 0.0 & 1.397 & -0.176511 & -0.186595 & $1.396 \mathrm{E}-4$ & -0.176496 & -0.186578 \\
\hline \multirow[t]{2}{*}{0.5} & $1.981 \mathrm{E}-3$ & -0.139955 & -0.235462 & $1.980 \mathrm{E}-3$ & -0.139947 & -0.235431 \\
\hline & \multicolumn{3}{|l|}{$G r=1$} & \multicolumn{3}{|l|}{$G r=25$} \\
\hline-0.5 & $-1.833 \mathrm{E}-4$ & $-2.232 \mathrm{E}-2$ & $-1.475 \mathrm{E}-2$ & $-2.384 \mathrm{E}-3$ & -0.548420 & -0.374106 \\
\hline 0 & $1.396 \mathrm{E}-7$ & $-1.769 \mathrm{E}-2$ & $-1.861 \mathrm{E}-2$ & $2.204 \mathrm{E}-3$ & -0.435648 & -0.473024 \\
\hline \multirow[t]{2}{*}{0.5} & $1.836 \mathrm{E}-4$ & $-1.402 \mathrm{E}-2$ & $-2.347 \mathrm{E}-2$ & $6.980 \mathrm{E}-3$ & -0.345835 & -0.598446 \\
\hline & \multicolumn{3}{|l|}{$B r=0.01$} & \multicolumn{3}{|l|}{$B r=2$} \\
\hline-0.5 & $-1.833 \mathrm{E}-3$ & -0.223195 & -0.147535 & $-1.548 \mathrm{E}-3$ & -0.221928 & -0.148194 \\
\hline 0.0 & 1.396 & -0.176947 & -0.186123 & $2.796 \mathrm{E}-4$ & -0.176071 & -0.187073 \\
\hline \multirow[t]{2}{*}{0.5} & $1.836 \mathrm{E}-3$ & -0.140262 & -0.234771 & $2.130 \mathrm{E}-3$ & -0.139644 & -0.236164 \\
\hline & \multicolumn{3}{|l|}{$\phi=0$} & \multicolumn{3}{|l|}{$\phi=0.05$} \\
\hline-0.5 & $-1.768 \mathrm{E}-3$ & -0.223664 & -0.141368 & $-1.573 \mathrm{E}-3$ & -0.220883 & -0.158478 \\
\hline 0.0 & $1.666 \mathrm{E}-4$ & -0.177393 & -0.178406 & $1.070 \mathrm{E}-4$ & -0.175171 & -0.199978 \\
\hline \multirow[t]{2}{*}{0.5} & $2.115 \mathrm{E}-3$ & -0.140659 & -0.225140 & $1.796 \mathrm{E}-3$ & -0.138887 & -0.252328 \\
\hline & \multicolumn{3}{|l|}{$A=0.5$} & \multicolumn{3}{|l|}{$A=2.0$} \\
\hline-0.5 & $-1.383 \mathrm{E}-3$ & -0.195880 & -0.129577 & $-1.841 \mathrm{E}-3$ & -0.235964 & -0.157072 \\
\hline 0 & $8.620 \mathrm{E}-5$ & -0.155109 & -0.163740 & $1.715 \mathrm{E}-4$ & -0.187263 & -0.198105 \\
\hline 0.5 & $1.562 \mathrm{E}-3$ & -0.122804 & -0.206906 & $2.198 \mathrm{E}-3$ & -0.148573 & -0.249841 \\
\hline
\end{tabular}

Table 1b. Values of skin friction with $D a=0.01, I=2, G r=10, B r=1, \phi=0.02, A=1$.

\begin{tabular}{|c|c|c|c|c|c|c|c|c|}
\hline \multirow[t]{2}{*}{$B V$} & $d w$ & $d w$ & $d w$ & $d w$ & $d w$ & $d w$ & $d w$ & $d w$ \\
\hline & $\left.d x\right|_{x=0}$ & $\left.d x\right|_{x=1}$ & $\left.d x\right|_{x=0}$ & $\left.d x\right|_{x=1}$ & $\left.d x\right|_{x=0}$ & $\left.d x\right|_{x=1}$ & $\left.d x\right|_{x=0}$ & $d x$ \\
\hline & \multicolumn{2}{|l|}{$C u$} & \multicolumn{2}{|l|}{$\mathrm{TiO}_{2}$} & \multicolumn{2}{|l|}{ Silver } & \multicolumn{2}{|l|}{ Diamond } \\
\hline-0.5 & $-1.357 \mathrm{E}$ & $57 \mathrm{~F} 2$ & $-1.339 \mathrm{E}-2$ & 220 & $1.361 \mathrm{E}-2$ & 1.36 & $-1.340 \mathrm{E}-2$ & $1.340 \mathrm{E}-2$ \\
\hline 0.0 & 16 & -9.1 & $810 \mathrm{E}-4$ & -8.8 & 9.2 & -9.2 & 8.725 & -8.72 \\
\hline \multirow[t]{2}{*}{0.5} & $1.547 \mathrm{E}-2$ & -1.54 & $1.523 \mathrm{E}-2$ & -1.5 & $1.553 \mathrm{E}-2$ & $-1.553 \mathrm{E}-2$ & $1.522 \mathrm{E}-2$ & $-1.522 \mathrm{E}-2$ \\
\hline & \multicolumn{2}{|c|}{$D a=0.00001$} & \multicolumn{2}{|l|}{$D a=1.0$} & \multicolumn{2}{|l|}{$I=0.0$} & \multicolumn{2}{|l|}{$I=10.0$} \\
\hline-0.5 & $-1.795 \mathrm{E}-3$ & $1.795 \mathrm{E}-3$ & $-2.201 \mathrm{E}-2$ & 2.20 & $-1.357 \mathrm{E}-2$ & $1.357 \mathrm{E}-2$ & $-1.357 \mathrm{E}-2$ & $1.357 \mathrm{E}-2$ \\
\hline 0.0 & $1.574 \mathrm{E}-6$ & $-1.574 \mathrm{E}-6$ & $7.140 \mathrm{E}-3$ & $-7.140 \mathrm{E}-3$ & $9.117 \mathrm{E}-4$ & $-9.117 \mathrm{E}-4$ & $9.112 \mathrm{E}-4$ & $-9.112 \mathrm{E}-4$ \\
\hline 0.5 & $1.798 \mathrm{E}-3$ & $-1.798 \mathrm{E}-3$ & $3.676 \mathrm{E}-2$ & $-3.676 \mathrm{E}-2$ & $1.547 \mathrm{E}-2$ & $-1.547 \mathrm{E}-2$ & $1.547 \mathrm{E}-2$ & $-1.547 \mathrm{E}-2$ \\
\hline
\end{tabular}


Table 1b (cont'd). Values of skin friction with $D a=0.01, I=2, G r=10, B r=1, \phi=0.02, A=1$.

\begin{tabular}{|c|c|c|c|c|c|c|c|c|}
\hline$B V$ & $\left.\frac{d w}{d x}\right|_{x=0}$ & $\left.\frac{d w}{d x}\right|_{x=1}$ & $\left.\frac{d w}{d x}\right|_{x=0}$ & $\left.\frac{d w}{d x}\right|_{x=1}$ & $\left.\frac{d w}{d x}\right|_{x=0}$ & $\left.\frac{d w}{d x}\right|_{x=1}$ & $\left.\frac{d w}{d x}\right|_{x=0}$ & $\left.\frac{d w}{d x}\right|_{x=1}$ \\
\hline & \multicolumn{2}{|l|}{$C u$} & \multicolumn{2}{|l|}{$\mathrm{TiO}_{2}$} & \multicolumn{2}{|l|}{ Silver } & \multicolumn{2}{|l|}{ Diamond } \\
\hline & \multicolumn{2}{|l|}{$G=1$} & \multicolumn{2}{|l|}{$G=25$} & \multicolumn{2}{|c|}{$B r=0.01$} & \multicolumn{2}{|l|}{$B r=2$} \\
\hline-0.5 & $-1.451 \mathrm{E}-3$ & $1.451 \mathrm{E}-3$ & $-2.188 \mathrm{E}-2$ & $2.188 \mathrm{E}-2$ & $-1.451 \mathrm{E}-2$ & $1.451 \mathrm{E}-2$ & $-1.264 \mathrm{E}-2$ & $1.264 \mathrm{E}-2$ \\
\hline 0.0 & $9.114 \mathrm{E}-7$ & $-9.114 \mathrm{E}-7$ & $1.438 \mathrm{E}-2$ & $-1.438 \mathrm{E}-2$ & $9.113 \mathrm{E}-6$ & $-9.113 E-6$ & $1.824 \mathrm{E}-3$ & $-1.824 \mathrm{E}-3$ \\
\hline \multirow[t]{2}{*}{0.5} & $1.452 \mathrm{E}-3$ & $-1.452 \mathrm{E}-3$ & $5.193 \mathrm{E}-2$ & $-5.193 \mathrm{E}-2$ & $1.452 \mathrm{E}-2$ & $-1.452 \mathrm{E}-2$ & $1.644 \mathrm{E}-2$ & $-1.644 \mathrm{E}-2$ \\
\hline & \multicolumn{2}{|l|}{$\phi=0$} & \multicolumn{2}{|l|}{$\phi=0.5$} & \multicolumn{2}{|l|}{$A=0.5$} & \multicolumn{2}{|l|}{$A=2.0$} \\
\hline-0.5 & $-1.352 \mathrm{E}-2$ & $1.352 \mathrm{E}-2$ & $-1.362 \mathrm{E}-2$ & $1.362 \mathrm{E}-2$ & $-1.365 \mathrm{E}-2$ & $1.365 \mathrm{E}-2$ & $-1.354 \mathrm{E}-2$ & $1.354 \mathrm{E}-2$ \\
\hline 0.0 & $1.033 \mathrm{E}-3$ & $-1.033 \mathrm{E}-3$ & $7.548 \mathrm{E}-4$ & $-7.548 \mathrm{E}-4$ & $7.540 \mathrm{E}-4$ & $-7.540 \mathrm{E}-4$ & $9.425 \mathrm{E}-4$ & $-9.425 \mathrm{E}-4$ \\
\hline 0.5 & $1.568 \mathrm{E}-2$ & $-1.568 \mathrm{E}-2$ & $1.5194 \mathrm{E}-2$ & $-1.519 \mathrm{E}-2$ & $1.522 \mathrm{E}-2$ & $-1.522 \mathrm{E}-2$ & $1.550 \mathrm{E}-2$ & $-1.550 \mathrm{E}-2$ \\
\hline
\end{tabular}

Table 1c. Values of rate of heat transfer with $D a=0.01, I=2, G r=10, B r=1, \phi=0.02, A=1$.

\begin{tabular}{|c|c|c|c|c|c|c|c|c|}
\hline \multirow[t]{2}{*}{$B V$} & $d \theta$ & $d \theta$ & $d \theta$ & $d \theta$ & $d \theta$ & $d \theta$ & $d \theta$ & $d \theta$ \\
\hline & $\left.d y\right|_{y=0}$ & $d y$ & $\left.d y\right|_{y=}$ & $d y$ & $d y$ & $d y$ & $d y$ & $d y$ \\
\hline & \multicolumn{2}{|l|}{$\mathrm{Cu}$} & \multicolumn{2}{|l|}{$\mathrm{TiO}_{2}$} & \multicolumn{2}{|l|}{ Silver } & \multicolumn{2}{|l|}{ Diamond } \\
\hline-0.5 & 0.540037 & 0.522735 & 0.534280 & 0.517483 & 0.540115 & 0.522689 & 0.539851 & 0.523044 \\
\hline 0.0 & 0.538962 & 0.521844 & 0.533236 & 0.516617 & 0.539033 & 0.521790 & 0.538806 & 0.522178 \\
\hline 0.5 & 0.538127 & 0.520699 & 0.532425 & 0.515506 & 0.538192 & 0.520637 & 0.537995 & 0.521067 \\
\hline & \multicolumn{2}{|c|}{$D a=0.00001$} & \multicolumn{2}{|l|}{$D a=1.0$} & \multicolumn{2}{|l|}{$I=0.0$} & \multicolumn{2}{|l|}{$I=10.0$} \\
\hline-0.5 & 0.530679 & 0.530311 & 0.554696 & 0.509874 & 0.540038 & 0.522735 & 0.540034 & 0.522737 \\
\hline 0.0 & 0.530650 & 0.530288 & 0.552175 & 0.507447 & 0.538963 & 0.521843 & 0.538960 & 0.521846 \\
\hline \multirow[t]{2}{*}{0.5} & 0.530627 & 0.530258 & 0.550214 & 0.504380 & 0.538128 & 0.520698 & 0.538126 & 0.520702 \\
\hline & \multicolumn{2}{|l|}{$G=1$} & \multicolumn{2}{|l|}{$G=25$} & \multicolumn{2}{|c|}{$B r=0.01$} & \multicolumn{2}{|l|}{$B r=2$} \\
\hline-0.5 & 0.530565 & 0.530392 & 0.587442 & 0.480615 & 0.530565 & 0.530392 & 0.549417 & 0.514920 \\
\hline 0.0 & 0.530554 & 0.530383 & 0.581745 & 0.474007 & 0.530554 & 0.530383 & 0.547334 & 0.513078 \\
\hline \multirow[t]{2}{*}{0.5} & 0.530546 & 0.530372 & 0.577420 & 0.465475 & 0.530546 & 0.530372 & 0.545720 & 0.510712 \\
\hline & \multicolumn{2}{|l|}{$\phi=0$} & \multicolumn{2}{|l|}{$\phi=0.5$} & \multicolumn{2}{|l|}{$A=0.5$} & \multicolumn{2}{|l|}{$A=2.0$} \\
\hline-0.5 & 0.510159 & 0.491773 & 0.587292 & 0.571531 & 0.538267 & 0.524214 & 0.540928 & 0.521987 \\
\hline 0.0 & 0.509021 & 0.490821 & 0.586309 & 0.570724 & 0.537372 & 0.523482 & 0.539764 & 0.521014 \\
\hline 0.5 & 0.508137 & 0.489599 & 0.585544 & 0.569687 & 0.536676 & 0.522542 & 0.538859 & 0.519765 \\
\hline
\end{tabular}

\section{Conclusions}

The problem of fully developed laminar flow in a duct filled with porous matrix and saturated with nanofluid was studied. The effect of all the pertinent parameters on the flow were observed along with the analysis of the physical characteristics such as volumetric flow rate, skin friction and heat transfer rate and the following conclusions were drawn.

1. The flow was enhanced as the viscosity variation parameter was increased immaterial of any of the nanoparticles.

2. The temperature contours were not distorted influentially with any of the governing parameters.

3. The flow was enhanced with the Darcy number, Grashof number, Brinkman number and aspect ratio whereas it was suppressed by the inertial and solid volume fraction parameters.

4. The volumetric flow rate was promoted with viscosity variation parameter, Darcy number, Grashof number, Brinkman number, aspect ratio but was demoted with the inertial parameter and solid volume fraction parameter.

5. The rate of heat transfer was increased at $y=0$ and decreased at $y=1$ with the increase in the values of Darcy number, Grashof number, Brinkman number, aspect ratio and reversal effect was observed with the inertial parameter for any value of the viscosity variation parameter. The heat transfer rate was pronounced at $y=0$ and 
also at $y=1$ with the solid volume fraction parameter. Optimum heat transfer was observed for Silver nanoparticle when compared with other nanoparticles.

6. The effects of viscosity variation parameter, Grashof number, Brinkman number and aspect ratio on the flow were the similar results observed by Umavathi and Odelu (2015d) in the absence of porous matrix for regular fluid. The effect of different nanoparticles and solid volume fraction agree with the results obtained by Umavathi and Sheremet (2016a) for nanofluids in the absence porous matrix. The effects of Darcy number and inertial parameter were in agreement with Umavathi (2013a) in the absence of nanoparticles.

\section{Acknowledgment}

Acknowledgment

J.C. Umavathi is thankful for the financial support under the UGC-MRP F.43-66/2014 (SR) Project

\section{Nomenclature}

A

a

b

c

$\mathrm{Br}$

$B V$

$D a$

Gr

I

$K$

$N x, N y$

$T$

$T_{0}$

$U, V, W$ velocity components

$u, v, w$

$X, Y, Z$

$x, y, z$

Greek symbols

$\theta$

$\rho$

$\kappa$

$\phi$

Subscripts

$n f$

$f$

$s$

\section{References}

Astanina, M.S., Sheremet, M.A., Umavathi, J.C., 2015c. Unsteady natural convection with temperature-dependent viscosity in a square cavity filled with a porous medium, TIPM, vol. 110, pp. 113-126.

Bejan, A., Dincer, I., Lorente, S., Miguel, A.F, Reis, A.H., 2004. Porous and Complex Flow Structures in Modern Technologies, Springer New York. dimensionless temperature

viscosity

density

permeability of the porous medium

solid volume fraction

thermo-physical properties of the nanofluids

base fluid

solid nanoparticles 
Brinkman C., 1947, On the permeability of media consisting of closed packed porous particles, Applied Ci. Research, Vol. 1, pp. 81-86.

Buongiorno, J., 2006. Convective transport in nanofluids, Journal of Heat Transfer, Vol. 128, pp. 240-250.

Brinkman, H.C., 1952. The viscosity of concentrated suspensions and solution, The Journal of Chemical Physics, Vol. 20, 571- 581, 1952

Chen, C.K., Lin, C.R., 1985. Natural convection from an isothermal vertical surface embedded in a thermally stratified highporosity medium, International Journal of Engineering Science, Vol. 33, pp. 131-138.

Eid, M.R., Abdel-Gaied, S.M., Idarous, A.A., 2015. On effectiveness chemical reaction on viscous flow of a non-Darcy nanofluid over a non-linearly stretching sheet in a porous medium, Jokull Journal, Vol. 65, pp. 76-92.

Eid, M.R., 2016. Chemical reaction effect on MHD boundary-layer flow of two-phase nanofluid model over an exponentially stretching sheet with a heat generation, Journal of Molecular Liquids, Vol. 220, pp. 718-725.

He, Y.R, Jin, Y., Chen, H.S., Ding, Y.L., Cang, D.Q., Lu, H.L., 2007. Heat transfer and flow behavior of aqueous suspensions of $\mathrm{TiO}_{2}$ nanoparticles (nanofluids) flowing upward through a vertical pipe, International Journal of Heat and Mass Transfer, Vol. 50, pp. 2272-2281.

Hady, F.M., Ibrahim, F.S., Abdel-Gaied, S.M., Eid, M.R., 2011a. Influence of yield stress on free convective boundarylayer flow of a non-Newtonian nanofluid past a vertical plate in a porous medium, Journal of Mechanical Science and Technology, Vol. 25, pp. 2043-2050.

Hady, F.M., Ibrahim, F.S., Abdel-Gaied, S.M., Eid, M.R., 2011b. Boundary-layer non-Newtonian flow over a vertical plate in a porous medium saturated with a nanofluid, Applied Mathematics and Mechanics (Eng. Edi.), Vol. 32, pp. 1577-1586.

Hady, F.M., Eid, M.R., Ahmed, M.A., 2014. A nanofluid flow in a non-linear stretching surface saturated in a porous medium with yield stress effect, Applied Mathematics and Information Science Letters, Vol. 2, pp. 43-51.

Herwing, H., Gersten, K., 1986. The effect of variable properties on laminar boundary-layer flow. Warme Stoffubertr, Vol. 20, pp. 47-52, 1986.

Hwang, K.S., Jang, S.P., Choi, S.U.S., 2009. Flow and convective heat transfer characteristics of water-based $\mathrm{Al}_{2} \mathrm{O}_{3}$ nanofluids in fully developed laminar flow regime, International Journal of Heat Mass Transfer, Vol. 52, pp. $193-199$.

Kaviany, S., 1995. Principles of Heat Transfer in Porous Media, Springer-Verlog, New York.

Lauriat, G., Prasad, V., 1987. Natural convection in a vertical porous cavity: A numerical study for Brinkman-extended Darcy formulation, Transactions of the ASME Journal of Heat Transfer, Vol. 109, pp. 295-320.

Lauriat, G., Prasad, V., 1989. Non-Darcian effects on natural convection in a vertical porous enclosure, International Journal of Heat and Mass Transfer, Vol. 32, pp. 2135-2148.

Li, Q., Xuan, Y.M., 2002. Flow and convective heat transfer characters of Cu-water nanofluid, Sci China Ser ETech Sci, 2002, Vol. 45, pp. 408-416.

Maxwell, J., 1904. A Treatise on Electricity and Magnetism, $2^{\text {nd }}$ ed., Oxford University Press, Cambridge, UK.

Nield, D.A., Kuznetsov, A.V., 2009. Thermal instability in a porous medium layer saturated by a nanofluid, International Journal of Heat Mass Transfer, Vol. 52, pp. 5796-5801.

Pop, I., Ingham, D.B., 2001. Convective Heat Transfer, Mathematical and computational Modeling of Viscous Fluids and Porous Media, Pergmon, Oxford.

Poulikakos, D., 1985. A departure from the Darcy model in boundary layer natural convection in a vertical porous layer with uniform heat flux, Transactions of the ASME Journal of Heat Transfer, Vol. 107, pp. 716-720.

Seddeek M.A., Effects of magnetic field and variable viscosity on forced non-Darcy flow about a flat plate with variable wall temperature in porous media in the presence of suction and bellowing, J. Appl. Mech. Tech. Phys., Vol. 43, pp. 13-17, 2002.

Tong, T.W., Subramaninan, E., 1985. Boundary layer analysis for natural convection in porous enclosure: use of Brinkman-extended Darcy model, International Journal of Heat and Mass Transfer, Vol. 28, pp. 563-571.

Umavathi, J.C., Kumar, J.P., Chamkha, A.J., Pop, I., 2005. Mixed convection in a vertical porous channel, Transport in Porous Media, Vol. 61, pp. 315-335.

Umavathi, J.C., Santosh Veershetty, 2012a. Mixed convection of a permeable fluid in a vertical channel with boundary conditions of third kind, Heat Transfer-Asian Research, Vol. 41, pp. 516-535.

Umavathi, J.C., Prathap Kumar, J., Jaweriya Sultana, 2012b. Mixed convection flow in a vertical porous channel with boundary conditions of third kind with heat source/sink, Journal of Porous Media, Vol. 15, pp. 998-1007.

Umavathi, J.C., 2013a. Effect of thermal modulation on the onset of convection in a porous medium layer saturated by a nanofluids, Transport and Porous Media, Vol., 98, pp. 59-79.

Umavathi, J.C., 2013b. Effect of time-periodic boundary temperature on the onset of nanofluid convection in a layer of a saturated porous medium, International Journal of Physical Science and Engineering, Vol. 7, pp. 1430-1435.

Umavathi, J.C., Shekar, M., 2013. Effect of MHD on Jeffery-Hamel flow in nanofluids by Differential Transform method, International Journal of Engineering Research and Applications, Vol. 3, pp.953-962. 
Umavathi, J.C., Liu, I.C., Sheremet, M.A., 2015. Convective heat transfer in a vertical rectangular duct filled with a nanofluid, HTAR, DOI:10.1002/htj.21182., 2015.

Umavathi, J.C., 2015a. Combined effect of variable viscosity and variable thermal conductivity on double diffusive convection flow of a permeable fluid in a vertical channel, TIPM, Vol. 108, 659-678.

Umavathi, J.C., 2015b. Free convective flow in a vertical rectangular duct filled with porous matrix for viscosity and conductivity variable properties, International Journal of Heat and Mass Transfer, Vol. 81, 383-403.

Umavathi, J.C., 2013c. Analysis of flow and heat transfer in a vertical rectangular duct using a non-Darcy model, Transport in Porous Media, Vol. 96, pp. 527-545.

Umavathi, J.C., 2013d. Heat transfer enhancement for free convection flow of nanofluids in a vertical rectangular duct using Darcy-Forchhiemer-Brinkman model, ICAPM Conference Proceeding, pp. 129-139.

Umavathi, J.C., Monica Mohite, B., 2014a. The onset of convection in a nanofluid saturated porous layer using Darcy model with cross diffusion, Meccanica, Vol. 49, pp. 1159-1175.

Umavathi, J.C., Monica Mohite, B., 2014b. Double diffusive convective transport in a nanofluid-saturated porous layer with cross diffusion and variation of viscosity and conductivity, HTAR, Vol. 43, pp. 628-652.

Umavathi, J.C., Monica Mohite, B., 2016. Convective transport in a porous medium layer saturated with a Maxwell Nanofluid, Journal of King Saud University, Engineering Sciences, Vol. 28, pp. 56-68.

Umavathi, J.C., 2015. Rayleigh-Benard convection subject to time dependent wall temperature in a porous medium layer saturated by a Nanofluid, Meccanica, Vol. 50, pp. 981-994.

Umavathi, J.C., Ojjelu Odelu, 2015d, Effect of variable viscosity on free convection in a vertical rectangular duct, International Journal of Heat and Mass Transfer, Vol. 84, pp. 1-15.

Umavathi, J.C., Shekar, M., 2016a. Combined effect of variable viscosity and thermal conductivity on free convection flow of a viscous fluid in a vertical channel using DTM, Meccanica, Vol. 51, pp. 71-86

Umavathi, J.C., Sheremet, M.A., 2016b. Influence of temperature conductivity of a nanofluids in a vertical rectangular duct, International Journal of Nonlinear Mechanics, Vol. 78, pp. 17-28.

Umavathi, J.C., Chamkha, A.J., Syed Moidduin, 2016c. Combined effect of variable viscosity and thermal conductivity on free convection flow of a viscous fluid in a vertical channel', International Journal of Numerical Methods for Heat \& Fluid Flow, Vol. 26, pp. 18-39

Vafai, K., Tien, C.L., 1981. Boundary and inertia effects on flow and heat transfer in porous media, International Journal of Heat and Mass Transfer, Vol. 24, pp. 195-203.

Wang, X.W., Xu, X.F., Choi, S.U.S., 1999. Thermal conductivity of nano-particle-fluid mixture, Journal of Thermophysics Heat Transfer, Vol. 13, pp. 474-480.

\section{Biographical notes}

Jawali C. Umavathi received her Ph.D. degree from Gulbarga University, Kalaburgi, India, in 1992 . She is a Professor in the Department of Mathematics, Gulbarga University, Kalaburgi, Karnataka, India. She is teaching for Post-Graduate students and guiding for Doctoral students since 1986. Her research interests include heat and mass transfer of multiple (Newtonian and non-Newtonian) fluids through channels and rectangular ducts, numerical simulation using finite differences and Range-Kutta Gill method, magnetohydradynamics, and flow through porous media, and stability analysis. She has published more than 170 papers in referred international journals. She has also presented more than 40 research papers in national and international conferences. She is a reviewer of many national and international journals She is currently dealing with few projects sponsored by University Grants Commission, Government of India. She has also worked as Post Doctoral Fellow in Italy sponsored by ERUSMUS MUNDUS-FUSION Project. She is a recipient of Kalapna Chawla Young Scientist award and Sir J.C. Bose Memorial award for her excellence in Fluid Mechanics.

Received January 2017

Accepted July 2017

Final acceptance in revised form January 2018 